This is the peer reviewed version of the following article:

Janković, B., Čupić, Ž., Jovanović, D., Stanković, M., 2016. Kinetic Analysis of Nonisothermal Reduction of Silica-Supported Nickel Catalyst Precursors in a Hydrogen Atmosphere. Chemical Engineering Communications 203, 182-199. https://doi.org/10.1080/00986445.2014.983268

This work is licensed under a Creative Commons Attribution Non Commercial No Derivatives 4.0 license 


\title{
Kinetic Analysis of Non-Isothermal Reduction of Silica-Supported Nickel Catalyst Precursors in a Hydrogen Atmosphere
}

\author{
Bojan Janković ${ }^{1}$, Željko Čupić ${ }^{2}$, Dušan Jovanović ${ }^{2}$, Miroslav Stanković ${ }^{2}$ \\ ${ }^{1}$ Faculty of Physical Chemistry, Department for Dynamics and Matter Structure, \\ University of Belgrade, Belgrade, Serbia, ${ }^{2}$ Institute of Chemistry, Technology and \\ Metallurgy, Center of Catalysis and Chemical Engineering, University of Belgrade, \\ Belgrade, Serbia
}

Faculty of Physical Chemistry, Department for Dynamics and Matter Structure, University of Belgrade, Studentski trg 12-16, P.O. Box 137, 11001 Belgrade, Serbia, Email: bojanjan@ffh.bg.ac.rs

\begin{abstract}
A series of silica-supported nickel catalyst precursors was synthesized with different $\mathrm{SiO}_{2} / \mathrm{Ni}$ molar ratios. Reduction of $\mathrm{Ni}$ catalyst precursors with different $\mathrm{SiO}_{2} / \mathrm{Ni}$ molar ratios under hydrogen atmosphere was investigated at different heating rates. Kinetic parameters were determined using Kissinger-Akahira-Sunose isoconversional and invariant kinetic parameters methods. It was found, that for all molar ratios, apparent activation energy $\left(E_{a}\right)$ is practically constant in conversion range of $0.20 \leq \alpha \leq 0.80$. In considered conversion range, following values of $\mathrm{E}_{\mathrm{a}}$ were found: $134.5 \mathrm{kJmol}^{-1}\left(\mathrm{SiO}_{2} / \mathrm{Ni}\right.$ $=0.20), 139.6 \mathrm{kJmol}^{-1}\left(\mathrm{SiO}_{2} / \mathrm{Ni}=0.80\right)$ and $128.3 \mathrm{kJmol}^{-1}\left(\mathrm{SiO}_{2} / \mathrm{Ni}=1.15\right)$. It was established that reduction of $\mathrm{Ni}$ catalyst precursors with different $\mathrm{SiO}_{2} / \mathrm{Ni}$ molar ratios is a complex process and can be described by Šesták-Berggren autocatalytic model. It was found that the reaction is more Langmuir-Hinshelwood type, as hydrogen dissociates rapidly on surface nuclei and dissociated hydrogen reacts with $\mathrm{Ni}-\mathrm{O}$ active system. It was concluded that reduction process proceeds through bulk nucleation which is dominant mechanism, where three-dimensional growth of crystals with polyhedron-like
\end{abstract}


morphology exist. It was found that $\mathrm{Ni} / \mathrm{Si}$ ratio decrease after the reduction process. This has been explained by low $\mathrm{Ni}$ and higher $\mathrm{Si}$ surface concentrations. It has been disclosed that Ni dispersion decreases.

KEYWORDS: Autocatalysis; Catalyst support; Complexity; Kinetics; Reduction

\section{INTRODUCTION}

Catalysis plays a pivotal role in the physical and biological sciences, in the industrial production of chemicals, 90\% of which are obtained via catalytic conversions (Thomas and Thomas, 1997). Catalysis research covers both multidisciplinary science and engineering.

In the field of heterogeneous catalysis, thermal analysis is used as a tool for investigating the influence of composition, preparation method and pre-treatment on the reactivity of catalyst surface or bulk with gases. Although thermal analysis is most frequently applied in the decomposition of solid materials, it also constitutes a suitable methodology to assess the kinetics of other thermally stimulated processes (Brown, 2001). Among thermo-analytical techniques, temperature-programmed desorption (TPD) and temperature-programmed reduction (TPR) are the tools that are most commonly used for characterizing heterogeneous catalysts. The temperature-programmed reduction (TPR) was inspired by the TPD technique and proposed in its present form by Robertson et al. (Robertson et al., 1975). In TPR, oxidic catalyst precursor is submitted to a programmed temperature rise (usually obeying the linear law represented as $T=T_{\mathrm{o}}+\beta t$, where $T$ is the 
absolute temperature, $T_{\mathrm{o}}$ is the initial temperature, $\beta$ is the temperature increase rate (linear heating rate) and $t$ is the time) under the flow of reducing gas mixture, and the consumption of the reducing agent is continuously monitored. Alongside catalyst characterization, temperature programmed techniques can be applied to mimic pretreatment procedures related to the operation of catalytic processes (Kapteijn et al., 1999). The application of TPD, TPR and related techniques was reviewed by Cvetanović and Amenomiya (Cvetanović and Amenomiya, 1972), Falconer and Schwarz (Falconer and Schwarz, 1983), Hurst et al. (Hurst et al., 1982), Lemaitre (Lemaitre, 1984) and Bhatia et al. (Bhatia et al., 1990).

Generally, temperature programming is better than flash methods in the fact that the time and temperature are interrelated in programming techniques. One can, therefore, deduce suitable kinetic expressions for a desorption process or for a process taking place as a result of temperature programming. In essence, temperature programming appears to provide a handle to discriminate various individual steps involved in desorption, reduction or oxidation processes while isothermal methods can provide information on the overall process that takes place.

Silica supported nickel catalysts are used extensively in many industrial processes such as hydrogenation of edible oils and aromatics in distillate fuels. As all these catalysts require optimized physical and chemical properties, a great deal of research has been reported with the aim of developing controlled catalyst preparation procedures. Continuous efforts are made and literature presents numerous works relating preparation methods, catalysts 
structure and catalytic behavior (González-Marcos et al., 1997; Gil et al., 1994; Che et al., 1995; Stevenson et al., 1989).

It was reported previously (Jovanović et al., 1998) that good hydrogenation catalysts could be obtained if $\mathrm{Ni}\left(\mathrm{NO}_{3}\right)_{2}$ is precipitated with $\mathrm{Na}_{2} \mathrm{CO}_{3}$ onto a $\mathrm{SiO}_{2}$ support (activated diatomite), with subsequent reduction in a hydrogen atmosphere. The possibilities for the characterization of the reduced catalysts are limited by their pyrophoric properties. Hence, after reduction, the catalyst must be passivated before any further manipulation. On the other hand, the precursor properties could be significantly changed during the reduction process, and the properties of the final catalyst are strongly dependent on the reduction conditions. More generally, the properties of the final catalyst, such as catalytic activity, selectivity etc., are strongly dependent on various process parameters used in the preparation treatment (Nele et al., 1999; Bhering et al., 2002; Fierro and Peña, 2005).

Bhering et al. (Bhering et al., 2002) used a statistical experimental setup to study the reduction step in the preparation of silica-supported nickel catalysts. These authors differentiated between precursors with weak nickel-support interactions and ones with strong nickel-support interactions. The strong metal support interactions were observed in a $\mathrm{SiO}_{2} / \mathrm{Ni}$ catalyst prepared via sol-gel synthesis (Ueckert et al., 1997; Gronchi et al., 2003). The weak interaction samples seem to be completely reduced even at low temperatures, while the strong interaction samples are reduced to different degrees at different temperatures due to high temperature stability of nickel silicate. In both cases, the specific area of the final catalyst depends strongly on the flow rate and hydrogen 
concentration. The formation of silicates should be avoided when highly reducible Ni precursors are supported. Therefore, low surface area silica supports and fast precipitation procedures (Butler et al., 1996) that result in supported basic nickel carbonate should be used. In addition, the mechanism of supported basic nickel carbonate reduction is not completely clear, and it is complicated by the fact that the reduction occurs in the temperature region corresponding to thermal decomposition of basic nickel carbonate. The kinetics of the reduction process could therefore give a new insight into the reaction mechanism of the investigated process and might lead to improvements of the catalysts (L'vov and Galwey, 2012).

The aim of this work is to perform kinetic analysis on non-isothermal reduction results for a series of silica-supported Ni-catalyst precursors, with different $\mathrm{SiO}_{2} / \mathrm{Ni}$ molar ratios $(0.20,0.80$ and 1.15$)$. The reduction of the investigated samples was studied by thermogravimetric analysis (TGA) with hydrogen as the reducing agent. Different kinetic models were tested against the experimental data and the kinetic parameters were estimated using different methods, as the integral isoconversional method (Kissinger, 1957; Akahira and Sunose, 1971), the invariant kinetic parameters (IKP) method (Lesnikovich and Levchik, 1983, 1985) and the kinetic method introduced by Málek’s (Málek, 1992). Also, in this paper, we will make a comparison of the results obtained with $\mathrm{SiO}_{2}$-supported and unsupported nickel catalysts during reduction process (Martin et al., 1981; Jackson et al., 1999; Weatherbee and Bartholomew, 1984; Janković et al., 2008). Also, we will discuss the possible contradictions in reduction kinetics of silicasupported and unsupported nickel catalysts (Zieliński, 1995; Geus, 1988). 


\section{EXPERIMENTAL PROCEDURE}

\section{Materials And Methods}

A series of nickel catalyst precursors with different $\mathrm{SiO}_{2} / \mathrm{Ni}$ molar ratio values $(0.20,0.80$ and 1.15) was synthesized according to a literature procedure (Jovanović et al., 1998). Nickel ions and promoter ions $(\mathrm{Mg})$ where precipitated at an elevated temperature $(90$ $\left.{ }^{\circ} \mathrm{C}\right)$ and at strictly defined $\mathrm{pH}$ conditions $(\mathrm{pH}=9.20)$, from a solution of $\mathrm{Ni}\left(\mathrm{NO}_{3}\right)_{2}$ and $\mathrm{Mg}\left(\mathrm{NO}_{3}\right)_{2}$ (molar ratio $\left.\mathrm{Mg} / \mathrm{Ni}=0.10\right)$ using $\mathrm{Na}_{2} \mathrm{CO}_{3}$ as the alkaline agent. The promoter role of $\mathrm{Mg}$ is in preventing the sintering of nickel $(\mathrm{Ni})$ particles during the reduction process.

Activated domestic diatomite with a low surface area was added to the reaction mixture as a support. Upon completion of the precipitation process, the filtered and rinsed precipitate was transferred to an oven and dried at the temperature of $120-140{ }^{\circ} \mathrm{C}$. The synthesis of the nickel catalyst supported on a natural silicate support (diatomite) is a three-stage process: the precursor synthesis, reduction, and passivation with impregnation. The preparation procedure is previously described in details (Jovanović et al., 1998). The calcinations step is omitted since the reduction of the original nickel basic carbonates is much easier than the reduction of $\mathrm{NiO}$. The passivation and impregnation steps are not the subject of the present research.

Diatomite, used as a support, was obtained from the Baroševac - Field B ("Kolubara" coal basin, Lazarevac, Serbia). Crude diatomite material was mechanically, chemically and thermally treated in order to obtain the activated support. Specific surface area of the 
support was $11.7 \mathrm{~m}^{2} \mathrm{~g}^{-1}$, while the total porosity was $66.6 \%$ with an average pore diameter of $495 \mathrm{~nm}$, as determined by mercury intrusion porosimetry (Stanković et al. 2009).

The reduction of all of the prepared samples was studied by thermogravimetry (TG) (Linseis Thermal Analyzer L75/L81/2000 with an automatic gas control system) at different heating rates $\left(\beta=2,5,10\right.$ and $\left.20{ }^{\circ} \mathrm{C} \mathrm{min}^{-1}\right)$ in a hydrogen flow with the rate of $\varphi$ $=50 \mathrm{~mL} \mathrm{~min}^{-1}$. Kinetic parameters for the catalyst reduced at different heating rates, can be used to explain the decrease of activity with the increasing of the heating rate.

Samples of the diatomite supported Ni catalyst with the highest value (1.15) of the $\mathrm{SiO}_{2} / \mathrm{Ni}$ were prepared for the characterization by the reduction in a gas mixture of $\mathrm{H}_{2} / \mathrm{N}_{2}$ $(1 / 1, \mathrm{v} / \mathrm{v})$ in an oven at $430{ }^{\circ} \mathrm{C}$ for $5 \mathrm{~h}$, after the heating with a rate of $1{ }^{\circ} \mathrm{C} \mathrm{min}{ }^{-1}$. For characterization in XPS (X-ray photoelectron spectroscopy) and SEM (scanning electron microscopy), a part of the activated catalyst was passivated in mixture of $350 \mathrm{ppm} \mathrm{O}_{2}$ in nitrogen at the room temperature over the time required for reducing the catalyst's pyrophority down to the level desirable for preventing self-ignition of the reducted nickel.

The electronic states of the nickel species on the surface of the catalysts were determined by XPS (X-ray photoelectron spectroscopy) analysis on a VG Scientific ESCALAB Mk II instrument. The pressure in the analytic chamber was maintained below $2.70 \times 10^{-6} \mathrm{~Pa}$ and the $\mathrm{Al} \mathrm{K}_{\alpha} \mathrm{X}$-ray excitation source $\left(h_{v}=1486.6 \mathrm{eV}\right)$ (operating at 
$15 \mathrm{kV}$ and $20 \mathrm{~mA}$ ) was used. The Lab Cal 2 software is used for the data analysis. The electronic binding energy data were amended by compensating charge with $\mathrm{C} 1$ peak at $284.6 \mathrm{eV}$. The resolution function of the instrument has been found to have a width of $0.35 \mathrm{eV}$ using the silver Fermi edge. To control charging of the samples, the charge neutralizer filament was used during all experiments. After calibration, the background from each spectrum was subtracted using a Shirley-type background to remove most of the extrinsic loss structure.

The scanning electron microscopy (SEM) analysis was performed on a JEOL Superprobe 733 microscope with a $25 \mathrm{kV}$ beam. The corresponding images are represented as a secondary electron imaging (SEI). The SEM is used to investigate the morphology and the uniformity of the particle shape, as well as to determine the chemical homogeneity of the supports.

Hydrogen chemisorption at $25^{\circ} \mathrm{C}$ was used to determine the nickel crystallite size and nickel surface area. The measurements were performed by the static method in a standard volumetric apparatus. The monolayer adsorption capacity was determined by extrapolation down to zero pressure with the linear regression of the equilibrium data in the range $0.1-13.3 \mathrm{kPa}$. The chemisorption measurements were carried out under the following conditions: in situ reduction of samples under a $\mathrm{H}_{2} / \mathrm{N}_{2}(1 / 1, \mathrm{v} / \mathrm{v})$ gas mixture stream at the heating rate of $2{ }^{\circ} \mathrm{C} \mathrm{min}^{-1}$. Description of the experimental procedure and discussion concerning its adequacy were provided elsewhere (Bartholomew, 1990; Bartholomew and Pannell, 1980; Hoang-Van et al., 1989). The nickel surface area was 
calculated using the equation in the form $S_{\mathrm{Ni}}\left(m_{\mathrm{Ni}^{2}} g_{\mathrm{Ni}}{ }^{-1}\right)=1.298 \times 10^{-19} \cdot N_{\mathrm{M}}$, where $N_{\mathrm{M}}$ is the number of hydrogen molecules adsorbed in the monolayer per gram of nickel. The above-stated equation was derived considering the surface occupied per atom of nickel as $6.33 \times 10^{-2} \mathrm{~nm}^{2}$ atom ${ }^{-1}$ (Coenen and Linsen, 1970), and the adsorption stoichiometry as 0.50 hydrogen molecules per surface nickel atom. The average size of the nickel crystallites $\left(d_{s \mathrm{Ni}}\right)$ in the catalyst was calculated assuming model in which hemispherical crystallites are attached to the support with their equatorial plane. For this model, the crystallite size (defined as the cube root of the volume) was calculated from the nickel area per gram of nickel $\left(S_{\mathrm{Ni}}\right)$ using the relation $d_{s \mathrm{Ni}}(\mathrm{nm})=431 / S_{\mathrm{Ni}}$ (Coenen and Linsen, 1970).

\section{Kinetic Analysis}

The temperature programmed reduction data is based on the understanding of gas-solid reaction mechanisms, which may include topochemical characteristics. In contrast to a homogeneous reaction, a topochemical reaction takes place at the interface between solid substrate and solid product. Reduction and oxidation reactions of solids may well exhibit topochemical dynamics, whereas adsorption and desorption on the catalytic surfaces are typically homogeneous reactions. Despite the differences in the intrinsic reaction mechanisms associated with various temperature-programmed techniques, the kinetic analyses largely share the same methodical basis.

The analysis of thermo-analytical data where there is a linear temperature rise $\left(\beta=\left(T-T_{\mathrm{o}}\right)\right.$ / $t$ ) has most often been based on the following rate equation: 
$\beta \frac{d \alpha}{d T}=A \exp \left(-\frac{E_{a}}{R T}\right) f(\alpha)$

which states that the rate of the reaction is proportional to the rate coefficient with an Arrhenius temperature dependence ( $\alpha$ is the degree of conversion, and is expressed as $\alpha=$ $\left(m_{\mathrm{o}}-m_{T}\right) /\left(m_{\mathrm{o}}-m_{f}\right)$, where $m_{o}, m_{T}$ and $m_{f}$ are the initial, actual (at the current temperature, $T$ ), and final mass of the sample, respectively; $A$ is the pre-exponential factor; $E_{a}$ is the apparent activation energy; $R$ is the gas constant and $T$ is the absolute temperature) and $f(\alpha)$ is the function of the degree of conversion. The function $f(\alpha)$ originates from physico-geometric considerations and/or the law of mass action. Table I collects alternative reaction models $f(\alpha)$ for solid-state kinetics and $g(\alpha)$, i.e. integrals of $1 / f(\alpha)$ (Brown et al., 1980; Vyazovkin and Wight, 1997).

The application of Eq. (1) is confined to the description of one intrinsic forward reaction or a set of consecutive reactions with one clearly rate-determining step that dominates over the whole range of conditions. The single-step model (Eq. (1)) often appears insufficient to describe the observed transformations. In addition, certain topochemical models cannot be presented in the functional form of Eq. (1) even though the intrinsic reaction is assumed to take place as a single-step forward reaction.

\section{Isoconversional (Model-Free) Technique}

The isoconversional (model-free) methods are advocated for their ability to provide estimates of the apparent activation energy independent of reaction mechanisms (Vyazovkin, 2000). The essence of the isoconversional methods is the acknowledgment of the complex nature of an overall solid-phase reaction and the inexpressibility of the 
apparent activation energy as a single constant (Vyazovkin, 2000). The isoconversional methods typically produce the apparent activation energy as a function of the degree of conversion. The interpretation of possible variable apparent activation energy in physicochemical terms poses serious difficulties. The overall reaction may involve one composite serial reactions scheme, where rate-controlling steps change with the reaction conditions. In addition, it may involve multiple parallel reactions with different reacting species or multiple parallel mechanisms for one reacting species. There are numerous other examples of overlapping chemical and/or physical elementary processes contributing to the overall dynamics. If the isoconversional analysis results in constant apparent activation energy, as a function of conversion, the reaction rate is presumably limited by a single rate determining step and it should be easy to discover the preexponential factor and the reaction mechanism. On the other hand, if the resulting apparent activation energy varies with conversion, then most simple mechanistic explanations are ruled out and it is useless to carry out model-fitting (Vyazovkin and Wight, 1999) with a single-step unidirectional reaction rate model. Evidently, then, the isoconversional methods do not contribute to the understanding of the underlying chemical phenomena. The utility of these methods remains an on/off measure of the simplicity/complexity of the examined reaction and the isoconversional methods only postpone the inevitable determination of a kinetic model.

In this paper, we have applied the Kissinger-Akahira-Sunose (KAS) integral isoconversional method (Kissinger, 1957; Akahira and Sunose, 1971). KAS method is 
based on the Coats-Redfern approximation of the Arrhenius integral (Coats and

Redfern, 1964). It was shown that:

$\ln \left(\frac{\beta}{T^{2}}\right)=\ln \left[\frac{A R}{E_{a} g(\alpha)}\right]-\frac{E_{a}}{R T}$

Thus, for $\alpha=$ const., the plot $\ln \left(\beta / T^{2}\right)$ versus $1 / T$, obtained from thermo-analytical curves recorded at the several heating rates, should be a straight line whose slope can be used to evaluate the apparent activation energy $\left(E_{a}\right)$ as a function of the degree of conversion $(\alpha)$ independently of the kinetic model fitted by the appropriate reaction.

Despite the popularity of the isoconversional methods applied to thermo-analytical data, true kinetic analysis must involve establishing a kinetic model and determining all its parameters. Reporting the apparent activation energy alone does not constitute the kinetic analysis. The value is meaningless until related to a mechanistic model and other kinetic parameters.

\section{Invariant Kinetic Parameters (Ikp) Method}

Invariant kinetic parameters (IKP) method (Lesnikovich and Levchik, 1983, 1985) requires several $\alpha-T$ curves recorded at different heating rates. The IKP method gives values of the invariant kinetic parameters, $E_{a, i n v}$ and $A_{i n v}$, which correspond to the true kinetic model that describes the investigated process at all heating rates (Budrugeac et al., 2004). It is based on the existence of the linear compensation effect (Eq.(3)) between $E_{a}$ and $\ln A$ obtained for the same thermogravimetric curve applying various theoretical kinetic models: 
$\ln A=\alpha^{*}+\beta^{*} E_{a}$

where $\alpha^{*}$ and $\beta^{*}$ represent the compensation effect parameters.

These values of $E_{a}$ and $\ln A$ can be obtained by using the Coats-Redfern (CR) (Coats and Redfern, 1964) method (Eq. (4)):

$\ln \left[\frac{g(\alpha)}{T^{2}}\right]=\ln \left(\frac{A R}{\beta E_{a}}\right)-\frac{E_{a}}{R T}$

For each theoretical kinetic model, $g(\alpha)$ (Table I), and each heating rate, $\beta$, from the slope and intercept of the plots $\ln \left[g(\alpha) / T^{2}\right]$ versus $1 / T$, the apparent activation energy $\left(E_{a}\right)$ and the pre-exponential factor $(A)$ can be found.

If the compensation effect exists, linear $\ln A$ versus $E_{a}$ dependence should be obtained for each heating rate and should intersect in a point that corresponds to the true values of kinetic parameters, for the true kinetic model, which are called the invariant kinetic parameters, $E_{a, i n v}$ and $A_{i n v}$ (Lesnikovich and Levchik, 1983, 1985). The intersection is only approximate due to the fact that certain variations of the experimental condition determine the region of intersection.

In order to eliminate the influence of experimental conditions on the determination of $E_{a, i n v}$ and $A_{i n v}$, they are determined from the slope and intercept of the supercorellation relation (Budrugeac et al., 2004):

$\alpha^{*}=\ln A_{i n v}-\beta^{*} E_{a, i n v}(5)$ 
The IKP method can be used only if the $E_{a}$ does not depend on $\alpha$, which must be previously checked by the isoconversional methods. Then, the IKP method can be used for the numerical evaluation of $f_{\text {inv }}(\alpha)$ function, by introducing the values of the invariant kinetic parameters $E_{a, i n v}$ and $A_{i n v}$ in Eq. (1). The shape of experimental curves $f_{i n v}(\alpha)$ versus $\alpha$ suggests the algebraic expression of $f(\alpha)$ function corresponding to the analyzed process.

\section{Determination Of The Kinetic Model}

Once the apparent activation energy has been determined, the kinetic model which best describes a measured set of TPR data can be found. Málek (Málek, 1992) has shown that for this purpose it is useful to define two special functions, designated as $y(\alpha)$ and $z(\alpha)$, which can easily be obtained by simple transformation of experimental data. Through the rearrangement of basic rate equation, $\mathrm{d} \alpha / \mathrm{d} t=A \exp \left(-E_{d} / \mathrm{R} T\right) f(\alpha)$, the function $y(\alpha)$ is defined as (Criado et al., 1989; Bulánek and Čičmanec, 2008):

$$
y=\frac{d \alpha}{d t} \exp \left(\frac{E_{a}}{R T}\right)=A f
$$

The $y(\alpha)$ function is proportional to the $f(\alpha)$ function. Thus, by plotting $y(\alpha)$ dependence, normalized within $[0,1]$ interval, the shape of the $f(\alpha)$ function is obtained. The $y(\alpha)$ function is, therefore, characteristic for a given kinetic $f(\alpha)$ model and it can be used as a diagnostic tool for the kinetic model determination. The nature of the $y(\alpha)$ function with respect to various kinetic model functions was reported previously (Málek, 1992). It should be stressed that the shape of the $y(\alpha)$ function is strongly affected by the $E_{a}$ value. Hence, the true apparent activation energy is decisive for a reliable determination of the 
kinetic model because of the correlation of the kinetic parameters (Málek, 1992). If the temperature rises at a constant rate $\beta$, the integration of Eq. (1) gives:

$$
g(\alpha)=\int_{0}^{\alpha} \frac{d \alpha}{f(\alpha)}=\frac{A E_{a}}{\beta R} \exp (-x)\left[\frac{\pi(x)}{x}\right]
$$

where $x=E_{a} / \mathrm{R} T$ represents the reduced apparent activation energy. By combining the basic rate equation and Eq. (7), an alternative kinetic equation is obtained

$$
\frac{d \alpha}{d t}=\left[\frac{\beta}{T \pi(x)}\right] f(\alpha) g(\alpha)
$$

After the rearrangement of Eq. (8), the $z(\alpha)$ function is defined as (Málek, 1989):

$$
z(\alpha)=\pi(x) \frac{d \alpha}{d t} \frac{T}{\beta}=f(\alpha) g(\alpha)
$$

where $\pi(x)$ is the approximation for the temperature (Arrhenius) integral. In this work, we used the fourth rational approximation of Senum and Yang for the $\pi(x)$ function (Senum and Yang, 1979).

The shape of the $y(\alpha)$ function as well as the maximum $\alpha_{p}^{\infty}$ of the $z(\alpha)$ function can be used as a guide to select the kinetic model. Both $\alpha_{m}$ (the maximum of the $y(\alpha)$ function) and $\alpha_{p}^{\infty}$ (the maximum of the $z(\alpha)$ function) parameters are especially useful in this respect. Their combination allows the determination of the most suitable kinetic model (Málek, 1992). The kinetic models D1, D2, D3, D4 (diffusion set of models) and RO(n) (reaction order set of models) have a maximum at $\alpha_{m}=0$ (Málek, 1992). On the other hand, the Johnson-Mehl-Avrami (JMA $(M))$ (Johnson and Mehl, 1939; Avrami, 1939, 1940, 1941) and the Šesták-Berggren $(\mathrm{SB}(m, n))($ Šesták and Berggren, 1971) models have a maximum at $0<\alpha_{m}<\alpha_{p}\left(\alpha_{p}\right.$ is the conversion value at the position of peak 
temperature $\left(T_{p}\right)$ value). For the JMA $(M)$ model, the relationship between the $\alpha_{m}$ value and the kinetic exponent $M$ is represented as (Málek, 1992):

$\alpha_{m}=1-\exp \left(\frac{1-M}{M}\right)$

It is expressed for the $\mathrm{SB}(m, n)$ reaction model as (Málek, 1992):

$\alpha_{m}=\frac{m}{m+n}$

where $m$ and $n$ represent the SB kinetic exponents (namely, in SB kinetic model expressed through the function $\alpha^{m}(1-\alpha)^{n}$, the involvement of reactants $(\alpha)$ and products $(1-\alpha)$ is attuned to their actual chemical transience $(m)$ and fertility $(n)$, which is timely adjusted by this type of power-law (Koga et al., 2013)). An important fact is that the $\alpha_{p}{ }^{\infty}$ is invariant with respect to the kinetic exponent for the JMA $(M)$ model. On the other hand, for both $\mathrm{RO}(n)$ and $\mathrm{SB}(m, n)$ reaction models, the parameter $\alpha_{p}^{\infty}$ depends on the values of kinetic exponents. It can be pointed out, that the Šesták-Berggren $(\operatorname{SB}(m, n))$ model gives the best description of the TPR data if $\alpha_{p}{ }^{\infty} \neq 0.632$ and $\alpha_{m}\left(0, \alpha_{p}\right)$ (Málek, 1989). In accordance with the above-mentioned properties of the $y(\alpha)$ and $z(\alpha)$ functions, these two functions allow to check the applicability of the conventional physicogeometry based kinetic models and to extend the kinetic understanding based on more sophisticated kinetic models.

\section{RESULTS AND DISCUSSION}

\section{Kinetic Conversion Curves Of Reduction Process}

The non-isothermal conversion curves of the investigated systems are shown in Fig. 1.

Only part of the thermo-analytical curves corresponding to the reduction process (the 
experimental curves are expressed in the form which is suitable for the kinetic analysis as $\alpha=\alpha(T))$ is presented. At lower temperatures $\left(T<150{ }^{\circ} \mathrm{C}\right)$ almost constant mass loss, corresponding to the loss of sorbed water, was observed for all the samples (13-15\%). Therefore, in Fig. 1, and subsequently, the relative mass loss, referring to the sample mass at the beginning of the reduction process was used.

The characteristic temperature values (the initial $\left(T_{i}\right)$, peak (inflection) $\left(T_{p}\right)$ and final $\left(T_{f}\right)$ temperature) of the reduction process for all investigated samples are shown in the Table II. It can be observed from Table II that all temperature values increase with increasing heating rate $(\beta)$, which is typical for the thermally activated heterogeneous systems.

From the results given in Fig. 1 and Table II, it can also be seen that the initial temperature of the reduction process depends on the heating rate $\beta$ and not on the $\mathrm{SiO}_{2} / \mathrm{Ni}$ molar ratio (Table II). On the other hand, the total mass loss depends on the $\mathrm{SiO}_{2} / \mathrm{Ni}$ mole ratio and not on the heating rate (Table III), indicating that the complete hydrogenation of all investigated samples was achieved.

In addition, assuming that the complete hydrogenation was achieved, the composition of the precursor samples was calculated from the total mass loss. The difference in the composition of the precursor samples probably originated from the synthesis procedure and conditions, and was calculated in accordance with the following stoichiometry:

$$
\mathrm{NiCO}_{3} \cdot X \mathrm{Ni} \mathrm{OH}{ }_{2} \cdot Y \mathrm{H}_{2} \mathrm{O}+1+\mathrm{X} \mathrm{H}_{2} \rightarrow 1+X \mathrm{Ni}+\mathrm{CO}_{2}+1+Y+2 X \cdot \mathrm{H}_{2} \mathrm{O}
$$


The precursor composition is expressed through the stoichiometric coefficients $X$ and $Y$ in a general formula of the form $\mathrm{NiCO}_{3} \cdot X \mathrm{Ni}(\mathrm{OH})_{2} \cdot Y \mathrm{H}_{2} \mathrm{O}$ (Table III). According to these results, the stoichiometric coefficients $X$ and $Y$ both increase with increasing $\mathrm{SiO}_{2} / \mathrm{Ni}$ molar ratio. However, more experimental measurements would be needed for the composition of the precursor samples to be characterized with much greater precision.

\section{Isoconversional Analysis}

Nevertheless, the obtained data of the thermo-analytical curves were analyzed in their normalized form and according to the basic thermal theory for the KAS method, the parameters $\alpha$ and $T$ were used to calculate the apparent activation energy $\left(E_{a}\right)$. The dependences of the apparent activation energy $\left(E_{a}\right)$ on the degree of conversion $(\alpha)$ for the reduction process of the silica-supported Ni-catalyst precursors with different $\mathrm{SiO}_{2} / \mathrm{Ni}$ molar ratios estimated by the KAS isoconversional method are shown in Fig. 2.

It can be seen that the value of the apparent activation energy for all observed mole ratio cases is practically constant in the conversion range of $0.20 \leq \alpha \leq 0.80$. In the considered conversion range, the following values of the apparent activation energy were found: $E_{a}=$ $134.5 \pm 5.1 \mathrm{~kJ} \mathrm{~mol}^{-1}\left(\mathrm{SiO}_{2} / \mathrm{Ni}=0.20\right), E_{a}=139.6 \pm 6.1 \mathrm{~kJ} \mathrm{~mol}^{-1}\left(\mathrm{SiO}_{2} / \mathrm{Ni}=0.80\right)$ and $E_{a}$ $=128.3 \pm 6.8 \mathrm{~kJ} \mathrm{~mol}^{-1}\left(\mathrm{SiO}_{2} / \mathrm{Ni}=1.15\right)$. It can be observed that for the highest molar ratio value $\left(\mathrm{SiO}_{2} / \mathrm{Ni}=1.15\right)$, the apparent activation energy value $\left(128.3 \mathrm{~kJ} \mathrm{~mol}^{-1}\right)$ is lower in comparison with $E_{a}$ for the other two molar ratio values. With the increase of the $\mathrm{SiO}_{2} / \mathrm{Ni}$ molar ratio, the value of the apparent activation energy $\left(E_{a}\right)$ decreases for about $\Delta E_{a}=8.7 \mathrm{~kJ} \mathrm{~mol}^{-1}$ (the average value). From the obtained results can be concluded that 
the increase of the $\mathrm{SiO}_{2} / \mathrm{Ni}$ molar ratio does not cause a drastic reduction of the $E_{a}$ value. On the other hand, for the conversion ranges of $\alpha<0.20$ and $\alpha>0.80$, small variations of the apparent activation energy $\left(E_{a}\right)$ value with $\alpha$ can be observed (Fig. 2).

For the reliable determination of the kinetic model of the investigated reduction process, the accurate value of the apparent activation energy must be determined. Therefore, applying the average value of $E_{a}$ within $\alpha$ from 0.20 to 0.80 , rather than within the entire range, was strongly recommended because most reactions, especially the solid-state ones, are not stable at the starting and ending periods. It can be pointed out, that as the process proceeds, reactants may undergo changes in reactivity due to the crystal defect formation, intra-crystalline strain and particle disintegration (Zhou et al., 2008). The reactivity of silica-supported nickel catalyst may not remain the constant, during the full course of reduction process. Therefore, we can expect some instability in the $E_{a}$ values obtained on the basis of isoconversional approach, especially at the lower values of conversion. However, the exact reason for this kind of noticed change in $E_{a}$ values at lower conversions will not be discussed at this stage. Accordingly, based on the abovementioned discussion, the average values of $E_{a}$ established in $\alpha$ range of $0.20 \leq \alpha \leq 0.80$ $\left(134.5,139.6\right.$ and $\left.128.3 \mathrm{~kJ} \mathrm{~mol}^{-1}\right)$ for all observed molar ratios, represent the most accurate values of the apparent activation energy.

It can be pointed out that the kinetics of reduction has extensively been investigated. Mass transport was often found to be partly or entirely rate determining (Szekely et al., 1973; Szekely and Evans, 1971; Yamashina and Nagamatsuya, 1966). The observed 
apparent activation energy was about $E_{a}=42 \mathrm{~kJ} \mathrm{~mol}^{-1}$. Lower values can generally be ascribed to mass transport limitation (Szekely et al., 1973; Delmon and Roman, 1973; Rooksby, 1943; Tien and Turkdogan, 1972). For reaction front propagation, the values of $E_{a}$ in the range of $117-120 \mathrm{~kJ} \mathrm{~mol}^{-1}$ were obtained (Rooksby, 1943). For nucleation the spread was much wider, reflecting the importance of the detailed structural perfection of the lattice and its surface: $120-188 \mathrm{~kJ} \mathrm{~mol}^{-1}$ (Delmon and Roman, 1973; Grange et al., 1969). It can be concluded that the obtained values of $E_{a}$ for all observed molar ratios, belong to the third group of the $E_{a}$ values (120-188 $\mathrm{kJmol}^{-1}$ ), which can be ascribed to the nucleation and growth processes, where the reduction under such conditions can favor the formation of Ni crystallites, modifying the surface properties of nickel. The above obtained values of $E_{a}$ estimated by the KAS method for various $\mathrm{SiO}_{2} / \mathrm{Ni}$ molar ratios directly correspond to the range of $E_{a}$ values belonging to reduction/oxidation processes attached to the nickel complex compounds (Wang et al., 2008). This result clearly shows us the quality and accuracy of calculated $E_{a}$ values reported for this type of process, related to the silica-supported nickel catalyst. Unlike the un-supported catalysts (Janković et al., 2008; L'vov and Galwey, 2012), in the current case, the higher values of $E_{a}$ were obtained. Namely, traditionally is believed that the rates of the gas-solid reactions are controlled either by the rates of molecular transport or by the chemical reaction rates on the solids (Misono, 2013). However, it should be noted that this assertion may not be valid in any case. Specifically, the fates and activities of surfaceformed radicals must be taken into account in order to successfully elucidate the kinetics and mechanisms of nickel oxide reduction (Janković et al., 2008; L'vov and Galwey, 2012). In the case when the radicals have little difficulties to desorb, desorption of 
radicals can effectively reduce the concentration of radicals on the solid surface to prolong the induction period and thus the overall reduction time of un-supported particles. However, in the presence of rigid pores structure of silica support, desorption of radicals out of the pores is greatly hindered. This can greatly contribute to slowing down the process, and demand for the higher energy to overcome the energy barrier, and thus contribute to the general increase in the effective (apparent) activation energy. In this case, the ease with which the surface-formed radicals migrate from its formation site to the silica-nickel boundary, can determines the rate of reduction the silica-supported nickel catalyst precursors. In this regard, we may note that higher values of $E_{a}$ in the current case than in the case of un-supported catalyst (Janković et al., 2008) can be attributed to the phenomenon of $\mathrm{Si}$ coverage on Ni(211) surface than that on pure $\mathrm{Ni}(111)$.

\section{The Ikp Analysis}

In order to apply the IKP method, the conversion range in which the value of $E_{a}$ is practically constant has to be determined and that has been done through the above method. For determining the compensation effect parameters $\left(\alpha^{*}, \beta^{*}\right)$, the Coats-Redfern method (Coats and Redfern, 1964) has been applied in the conversion range where $E_{a}$ is independent of the degree of conversion $(0.20 \leq \alpha \leq 0.80)$. The values of kinetic parameters of the reduction process ( $\ln A$ and $E_{a}$ ), calculated for the considered set of reaction models (Table I) at different heating rates $\left(\beta=2,5,10\right.$ and $\left.20{ }^{\circ} \mathrm{Cmin}^{-1}\right)$ are also provided [Supplementary data (Tables I, II and III in the frame of supplementary data)]. 
It was found that for all investigated $\mathrm{SiO}_{2} / \mathrm{Ni}$ molar ratios, the values of the kinetic parameters ( $\ln A$ and $E_{a}$ ) are strongly determined by the form of assumed $g(\alpha)$. As a result, almost any $g(\alpha)$ function can satisfactorily fit data at the cost of drastic variations in the kinetic parameters, which compensate for the difference between the assumed form of $g(\alpha)$ and the true, but in that case unknown reaction model. It was found that in the case of reduction processes for $\mathrm{SiO}_{2} / \mathrm{Ni}=0.20$ and $\mathrm{SiO}_{2} / \mathrm{Ni}=0.80$, the best (statistically equivalent) reaction models at all heating rates are F3/2 and F2 [Supplementary data (Tables I and II in the frame of supplementary data)]. On the other hand, for the reduction process on $\mathrm{SiO}_{2} / \mathrm{Ni}=1.15, \mathrm{~F} 1, \mathrm{~F} 3 / 2$ and $\mathrm{F} 2$ models represent the best (statistically equivalent) reaction models [Supplementary data (Table III in the frame

\section{of supplementary data)].}

However, calculated values of the apparent activation energies, $E_{a}$ [Supplementary data (see provided Tables)], are not in agreement with the values of $E_{a}$ calculated by the KAS isoconversional method, which means that none of the tested reaction models corresponds to the real reaction model for the reduction process of silica-supported nickel catalyst precursors with different $\mathrm{SiO}_{2} / \mathrm{Ni}$ molar ratios. The apparent compensation effect was observed for all of the investigated systems at each of the observed heating rates, and corresponding $\ln A$ versus $E_{a}$ dependences were analyzed (not shown).

A compensation effect of this kind is classified as a false or superficial compensation effect (Koga and Šesták, 1991) resulting from the parameter distortion by an inappropriate kinetic model function. The values of $\alpha^{*}$ and $\beta^{*}$ were calculated from the 
intercepts and the slopes of the evaluated straight lines. The values of the apparent compensation effect $\left(\alpha^{*}, \beta^{*}\right)$ obtained at different heating rates $(\beta)$, for all considered $\mathrm{SiO}_{2} / \mathrm{Ni}$ molar ratios are listed in Table IV. In the same table, the corresponding values of the isokinetic temperatures, $T_{i s o}\left(T_{i s o}=1 / \beta^{*} R\right)$ are also presented.

It can be seen from Table IV, that the value of $\beta^{*}$ parameter decreases with increasing heating rate $(\beta)$, which causes the increase of the $T_{\text {iso }}$ value for all observed $\mathrm{SiO}_{2} / \mathrm{Ni}$ molar ratios. When studying the kinetics of reactions of the same type using the correct $f(\alpha)$ (or $g(\alpha))$ function, the straight lines characterizing the kinetics of these reactions usually cross at a point with co-ordinates $\ln k_{i s o}\left(=\alpha^{*}\right)$ and $1 / T_{i s o}$. This point corresponds to the isokinetic temperature $T_{i s o}$, at which the rate constants of the reactions have the same value $-k_{i s o}$. This means that at temperatures higher than $T_{i s o}$, the reactions occurring at higher $E_{a}$ would have higher rate (higher rate constants) than those with lower apparent activation energies (at the beginning of the reduction process for $\alpha$ values of up to $\alpha=$ 0.20 (Fig. 2)).

A linear regression from the straight line plot of $\alpha^{*}=\ln A_{i n v}-\beta^{*} E_{a, i n v}$ allows the computation of the invariant kinetic parameters (the invariant pre-exponential factor, $A_{i n v}$, and the invariant apparent activation energy, $\left.E_{a, i n v}\right)$. As $\alpha^{*}$ and $\beta^{*}$ are correlated by the supercorrelation relation, the corresponding values of the invariant kinetic parameters for all investigated $\mathrm{SiO}_{2} / \mathrm{Ni}$ molar ratios can be estimated and these values are presented in Table V. 
The obtained values of the invariant activation energy, $E_{a, \text { inv }}($ Table $\mathbf{V})$ are in good agreement with values of $E_{a}$ calculated by the KAS isoconversional method for all observed $\mathrm{SiO}_{2} / \mathrm{Ni}$ molar ratios (the difference between these values does not exceed $10 \mathrm{~kJ}$ $\mathrm{mol}^{-1}\left(\Delta E_{a}<10 \mathrm{~kJ} \mathrm{~mol}^{-1}\right)$ which represents a acceptable deviation). On the other hand, the values of the pre-exponential factor for solid phase reactions are expected to be in a wide range (six or seven orders of magnitude). In that case, the pre-exponential factors may vary from $10^{4}$ to $10^{18} \mathrm{~min}^{-1}$ (Vlaev et al., 2007). The lower pre-exponential factors will often indicate a surface reaction, but if the reactions are not dependent on surface area, a low factor may indicate a 'tight' complex. The higher pre-exponential factors will usually indicate a 'loose' complex (Vlaev et al., 2007). The higher pre-exponential factors (after correction of surface area) can be also being obtained, if the complexes have free translation on the surface. Since the concentrations in the solid are not controllable in many cases, it would be convenient if the magnitude of the preexponential gave an indication of the molecularity. This appears to be true only for nonsurface-controlled reactions having low $\left(<10^{9} \mathrm{~min}^{-1}\right)$ pre-exponential factors. Based on the facts above, we can conclude that the reduction process of silica-supported nickel catalyst precursors in a hydrogen atmosphere was governed by the surface-controlled reactions (> $10^{9} \mathrm{~min}^{-1}$ (Table V)).

Since none of the considered reaction models (Table I) can fully describe thermoanalytical data, the values of the invariant kinetic parameters were used for the further numerical evaluation of $f(\alpha)$ function. 
Fig. 3 shows the curves $f_{\text {inv }}(\alpha)$ versus $\alpha$ obtained from Eq. (1) at different heating rates for all investigated $\mathrm{SiO}_{2} / \mathrm{Ni}$ molar ratios, using the experimental values of $\beta(\mathrm{d} \alpha / \mathrm{d} T)$ and the values of the invariant kinetic parameters, $A_{i n v}$ and $E_{a, i n v}($ Table V).

As shown in this figure, for all investigated systems and for all heating rates $(\beta)$, the curves $f_{\text {inv }}(\alpha)$ versus $\alpha$ exhibit the same shape, which indicates the same reduction mechanism and shows the corresponding dependences on the heating rate.

It is clear from the Fig. 3 that the curve $f_{\text {inv }}(\alpha)$ versus $\alpha$ exhibits a maximum (designated by the arrow symbols (Fig. 3)), suggesting that the reduction of silica-supported nickel catalyst precursors in a hydrogen atmosphere occurs through the reaction mechanism which is similar to the mechanism represented by the JMA $(M)$ model (for $M>1$ ). An inspection of the reaction mechanism functions included in Table I clearly confirms that only in these cases do the $f(\alpha)$ versus $\alpha$ curves have a maximum at:

$f^{\prime}(\alpha)=\frac{d f(\alpha)}{d \alpha}=0$

Comparing Eq. (13) with the different form of the respective $f(\alpha)$ (Table I), D1, D2, D3, D4 and $\mathrm{RO}(n)$ models have a maximum at $\alpha_{\max }=0$ (Málek, 1992). Bearing in mind the results presented in Fig. 3, we can eliminate both the diffusion and reaction order models from the further consideration. On the other hand, the $\operatorname{JMA}(M)$ and $\mathrm{SB}(m, n)$ kinetic models have a maximum between 0 and $\alpha_{p}$ (Málek, 1992).

Accurate Determination Of Reduction Mechanism 
In order to determine the most reliable kinetic model which best describes the investigated reduction process of silica-supported nickel catalyst precursors, we apply the two special functions $(y(\alpha)$ and $z(\alpha))$ introduced by Málek (Málek, 1992).

The dependence of $y(\alpha)$ and $z(\alpha)$ functions on the degree of conversion $(\alpha)$ for the reduction process of silica-supported nickel catalyst precursors with different $\mathrm{SiO}_{2} / \mathrm{Ni}$ molar ratios, are shown in the Figs. 4-9.

A concave shape for all $y(\alpha)$ functions under analysis was identified (Figs. 4-6), which means that $\alpha_{\mathrm{m}} \neq 0$ and makes the use of the $\operatorname{JMA}(M)$ or $\mathrm{SB}(m, n)$ kinetic models possible. On the other hand, all the $z(\alpha)$ functions exhibit well-defined maxima (Figs. 7-9), where for the $\mathrm{SiO}_{2} / \mathrm{Ni}=1.15$, we can observe a considerable dependence on the heating rate, especially for the higher heating rates $\left(10\right.$ and $\left.20{ }^{\circ} \mathrm{C} \min ^{-1}\right)($ Fig. 9). For the construction of $y(\alpha)$ and $z(\alpha)$ plots, the value of the invariant activation energy $E_{a, i n v}$ was used. The values of $\alpha_{m}, \alpha_{p}^{\infty}$ and $\alpha_{p}$ estimated for the temperature-programmed reduction of silicasupported nickel catalyst precursors under hydrogen atmosphere are shown in Table VI.

It can be observed that the value of the parameter $\alpha_{m}$ at all heating rates falls in the range of $0<\alpha_{m}<\alpha_{p}$, while the parameter $\alpha_{p}^{\infty}$ exhibits the values lower than $0.632\left(\alpha_{p}^{\infty} \neq\right.$ $0.632)$, which represents the characteristic $\alpha_{p}{ }^{\infty}$ value for the JMA $(M)$ model. The kinetic model determination by the combination of $y(\alpha)$ and $z(\alpha)$ is especially suitable for the nucleation-growth processes, having the capability of distinguishing the SB models from the JMA models as complicated nucleation-growth processes, the present kinetic analysis 
exemplifies the successful application of the method to the non-isothermal reduction of silica-supported nickel catalyst precursors.

From the obtained results, we can conclude that the reduction of silica-supported nickel catalyst precursors in a hydrogen atmosphere, must be described with a more sophisticated kinetic model as the two-parameter Šesták-Berggren $(\operatorname{SB}(m, n))$ autocatalytic model (Šesták and Berggren, 1971). In this respect, the two-parameter Šesták-Berggren $(\mathrm{SB}(m, n))$ reaction mechanism function, $f(\alpha)$, can be presented as (Šesták and Berggren, 1971):

$f(\alpha)=\alpha^{m}(1-\alpha)^{n}$,

in which $m+n$ is called the order of reaction. The $m$ and $n$ exponents are adopted as kinetic parameters which describe the shape of measured thermo-analytical curves. This model can be understood in terms of the accommodation function (Koga and Málek, 1996) expressing a deviation from the ideal case due to a more complex process. In that sense, the $\mathrm{SB}(m, n)$ function has an empirical character, which in turn makes it possible to describe various types of shape of thermo-analytical curves. Therefore, the SB kinetic model can be used for a quantitative description of more complex crystallization processes involving partially overlapping nucleation and growth phases. It has been shown by Málek (Málek et al., 1989) that the physically meaningful values of the parameter $m$ should be confined in the range of $0<m<1$. On the other hand, the parameter $n$ is normally an integer, which for simple reactions ranges from 0 to 3 . In contrast to the homogeneous reactions, the fractional reaction orders are often observed in the case of the heterogeneous reactions. 
Rearrangement of Eq. (11) gives the ratio of kinetic exponents, $p=m / n$ :

$$
p=\frac{\alpha_{m}}{1-\alpha_{m}}
$$

From Eq. (6), we obtain:

$\ln y(\alpha)=\ln A+n \ln \left[\alpha^{p}(1-\alpha)\right]$

The kinetic parameter $n$ corresponds to the slope of the linear dependence of $\ln y(\alpha)$ versus $\ln \left[\alpha^{p}(1-\alpha)\right]$ for the conversion range of $0.20 \leq \alpha \leq 0.80$. Then, the second kinetic parameter is $m=p \cdot n$. From the intercept of the linear dependence presented by Eq. (16), the value of the pre-exponential factor $(A)$ can be calculated.

Table VII lists the values of kinetic exponents ( $m$ and $n$ ), the values of reaction orders ( $m$ $+n)$ as well as the values of $A$ (with their average values) obtained by the procedure described above, for reduction process of silica-supported nickel catalyst precursors with different molar ratios.

It can be observed from Table VII that the values of SB kinetic exponents ( $m$ and $n$ ) as well as the values of reaction orders $(m+n)$ depend on the heating rates for all considered molar ratios, while the values of $A$ do not show large variations with heating rate (order of magnitude from $10^{11}$ to $10^{13}$ ). On the other hand, in the respect to the average values, both the values of the kinetic exponents ( $m$ and $n$ ) and reaction orders ( $m$ $+n$ ) decrease with increasing $\mathrm{SiO}_{2} / \mathrm{Ni}$ molar ratio (Table VII). 
Based on the obtained results, we decided that $f(\alpha)=\alpha^{0.50}(1-\alpha)^{1.42}, f(\alpha)=\alpha^{0.48}(1-\alpha)^{1.14}$ and $f(\alpha)=\alpha^{0.42}(1-\alpha)^{1.06}$ indeed are the best conversion functions for $\mathrm{SiO}_{2} / \mathrm{Ni}=0.20,0.80$ and 1.15, respectively, because according to Šesták et al. (Šesták et al., 1973), in the case of a system that contains metallic particles, the reduction processes take place mainly along the border between the oxide and the metallic particles.

It can be pointed out that quantitative X-ray analysis of passivated reduced $\mathrm{SiO}_{2} / \mathrm{Ni}$ catalysts, showed that the amount of nickel oxide was proportional to the nickel surface area before passivation, indicating that the oxide found was present on the surface of the nickel crystallites and was formed in passivation (Delmon, 1979). Thus, in the nonpassivated reduced catalyst no nickel oxide was present and incomplete reduction was located in the silicate foundation structure. This led to the conclusion that an oxide particle, derived from hydroxide by dehydration, once its reduction is initiated, is reduced completely (Dalmai-Imelik et al., 1976).

From the established Sesták-Berggren (SB) parameters $(m, n)$, we can evaluate the reduction mechanism of silica-supported nickel catalyst precursors with different $\mathrm{SiO}_{2} / \mathrm{Ni}$ molar ratios. It can be seen from Table VII that for the molar ratio $\mathrm{SiO}_{2} / \mathrm{Ni}=0.20$, the value of $n$ parameter was $=1.42$ (the average value). This value means that the removal of oxygen from the surface involves hydrogen adsorption in the corresponding vicinity of the oxygen. This means that hydrogen adsorption in the vicinity of $\mathrm{NiO}_{\mathrm{x}}$ species becomes the rate-limiting reaction step. It could be considered as an inducing process that initiates the reduction process. With the increase of the $\mathrm{SiO}_{2} / \mathrm{Ni}$ molar ratio up to 1.15 , the $n$ 
parameter decreases and drops down to $\approx 1.00$. This fact could mean an acceleration of the reaction between the adsorbed hydrogen and the oxygen that belongs to the silica surface. These two changes also suggest that $\mathrm{NiO}_{\mathrm{x}}$ species could promote the reduction of $\mathrm{SiO}_{2}$. It should be expected, that hydrogen molecules were adsorbed with a moderate strength on $\mathrm{SiO}_{2} / \mathrm{Ni}$ (in comparison with $\mathrm{MgO} / \mathrm{Ni}$ catalyst, for example) and were properly activated (Liu et al., 2007; Nakagawa et al., 2012). On the other hand, the values of $m$ parameter are different comparing to the $n$ values at all the $\mathrm{SiO}_{2} / \mathrm{Ni}$ molar ratios, which exhibit the decreasing trend behavior (taking into account the average value) (Table VII). Different values of this parameter suggest that the influence of nickel particles varies depending on the $\mathrm{SiO}_{2} / \mathrm{Ni}$ molar ratio.

According to the considerations above, when there are metallic particles on the surface of the oxide, one can be sure that the reduction process is taking place mainly around them. Yet, the possibility that some sites of the oxide surface that are far from the metallic particles are involved in the reduction process cannot be excluded. In other words, both the contracting sphere model (Hurst et al., 1982) and the autocatalytic model have to be applied in that case.

Furthermore, the SB kinetic exponents ( $m$ and $n$ ) should be linked with the mechanism of reduction process, but due to the empirical nature of the SB model such links are hard to find in the literature. However, some recent studies (Munteanu et al., 2004; Munteanu and Segal, 2010) has attempted to relate the $\mathrm{SB}(m, n)$ exponents to the structure of the considered material. Comparing the kinetic exponents, it can be seen that the average $n$ 
value decreases from 1.42 to 1.06 , going from $\mathrm{SiO}_{2} / \mathrm{Ni}=0.20$ to $\mathrm{SiO}_{2} / \mathrm{Ni}=1.15$, respectively (Table VII). This behavior may indicate that the decreasing of $n$ leads to an increase in crystallite sizes (Munteanu and Segal, 2010), with $\mathrm{SiO}_{2} / \mathrm{Ni}$ order: $0.20 \rightarrow$ $0.80 \rightarrow 1.15$. It has been proposed such a shift of $n$ value indicates the shift of the mechanism from Langmuir-Hinshelwood to Eley-Rideal (Munteanu and Segal, 2010). On the other hand, the average $m$ value decreases from 0.50 to 0.42 , going from $\mathrm{SiO}_{2} / \mathrm{Ni}$ $=0.20$ to $\mathrm{SiO}_{2} / \mathrm{Ni}=1.15$ (Table VII). This leads to a lot less (not as effective) role of the reduced phase in the overall reduction process, for the case of $\mathrm{SiO}_{2} / \mathrm{Ni}=1.15$ ratios.

The macroscopic process of reduction (nucleation/crystal growth) strongly depends on the concentration and distribution of nuclei in the sample. The nuclei can be of the two types, surface nuclei and the bulk nuclei. The surface nuclei are already present on the sample, while the bulk nuclei, termed as secondary nuclei, form during the course of reduction. To gain a better insight into the reaction mechanism, the proper morphological examination of the resulting reduction product and the corresponding chemisorption tests were performed.

\section{Sem Analysis}

The SEM image of as-synthesized $\mathrm{Ni} / D$ precursors $(D$ is the label for diatomite as a source of $\mathrm{SiO}_{2}$ ) is shown in Fig. 10.

As can be seen in Fig. 10 that as-synthesized precursor displays well-pronounced habit. The surface consists of fragments different in shape and size. The larger ones have an 
effective diameter in the range 3-7 $\mu \mathrm{m}$. These are covered with numerous fine particles with an effective diameter from 0.5 to $3 \mu \mathrm{m}$.

The SEM image of reduced $\mathrm{Ni} / D$ precursor (Fig. 11) annealed at $430{ }^{\circ} \mathrm{C}$ demonstrates visible changes in its morphology after reduction and passiviation. The sample undergoes significant packing in result of water and $\mathrm{CO}_{2}$ removing. The large aggregates are covered with small particles of similar size and shape as in the case of the non-reduced precursor (Fig. 10).

The both SEM images (Figs. 10 and 11) are provided with $\times 2000$ magnification and with a marker length equal to $15 \mu \mathrm{m}$. The almost round fragment is with sizes: length $\approx$ $4.9 \mu \mathrm{m}$ and width $\approx 4.2 \mu \mathrm{m}$. The effective diameter $\left(d_{e f f}\right)$ is approximately $4.9 \mu \mathrm{m}$.

It can be pointed out that the powder X-ray diffraction analysis (Deraz et al., 2009) shows that nickel catalyst supported on silica with different Ni loading resulted in an increase in the degree of ordering of Ni phase. In other words, it means that the increasing amounts of impregnate (Ni) facilitate the agglomeration process of $\mathrm{Ni}$ crystallites to the extent approximately proportional to the amount of nickel loaded. Specifically, this may be associated with the dispersion of nickel species available for the catalyzed reaction. However, the above-mentioned fact can significantly affects the kinetic developments of the entire reduction process, due to the different molar ratios of $\mathrm{SiO}_{2} / \mathrm{Ni}$. Therefore, according to this relation, we can expect that there will be a greater or a lesser extent, to reach the segregation of Ni particles at the catalyst surface. To verify 
the validity of these claims, the additional experimental characterization of samples were performed.

\section{Chemisorption Analysis}

In chemisorption measurements, the total hydrogen uptake were determined from the zero pressure intercepts of the isotherms, thus eliminating any reversible adsorption, particularly that on the support.

The chemisorption results of $\mathrm{Ni} / D$ sample are listed in Table VIII.

It should be emphasized that the estimation of metal crystallite size from hydrogen uptake requires that assumptions be made regarding metal crystallite morphology. To calculate the average crystallite size, it was assumed hemispherical shape of nickel crystallites which is suitable for the supported catalysts with strong metal-support interaction. The average size of nickel crystallite of the studied catalysts deduced by static hydrogen chemisorption method was confirmed by XRDLB method (Table VIII). It may be noted the existence of a fairly large area of the metallic nickel surface, wherein the release of the nickel active sites for hydrogen uptake increasing $\left(744.00 \mu \mathrm{mol} \mathrm{g}_{\mathrm{Ni}}{ }^{-1}\right.$ (Table VIII)). From these results we can conclude that the structure sensitivity does not affect on the kinetics of hydrogen $\left(\mathrm{H}_{2}\right)$ adsorption of Ni surfaces. In addition, the agreement between results obtained with the different techniques leads us to conclude that no changes in $\mathrm{H}-\mathrm{Ni}$ stoichiometry took place. 
Because of the low crystallite size and high surface area of $\mathrm{Ni} / D$ sample, the surface nuclei initiate the reaction early. Thus, the reaction is more Langmuir-Hinshelwood type, as hydrogen dissociates rapidly on the surface nuclei and the dissociated hydrogen reacts with Ni-O active system. For this case, the important process is the reaction of the adsorbed hydrogen and the surface nuclei, probably the oxygen vacancies. This is indicated with a fairly high value of $n$, particularly at $\mathrm{SiO}_{2} / \mathrm{Ni}=0.20$ molar ratios (Table VII). For $\mathrm{SiO}_{2} / \mathrm{Ni}=1.15$ sample, the number of oxygen vacancies and correspondingly the surface nuclei are small. But as its reduction happens at the higher temperature, a larger number a bulk nuclei are formed. These bulk nuclei which are present inside $\mathrm{NiO}_{\mathrm{x}}$ crystals tend to grow much faster. The decline averaged values of $m$ with an increasing of $\mathrm{SiO}_{2} / \mathrm{Ni}$ molar ratio (Table VII) indicates a decrease in Ni concentration within the reaction and also to reduce the concentration of $\mathrm{Ni} / \mathrm{Mg}$-base carbonate, which can be due to the absence of specific interactions between the active components in the reaction system.

It has been shown (Šesták et al., 1973) that the Šesták-Berggren $(\operatorname{SB}(m, n))$ equation is equivalent to the $\operatorname{JMA}(M)$ equation to a first approximation. The $\mathrm{SB}(m, n)$ model thus includes JMA $(M)$ model as a special case (Málek, 1989) and the kinetic parameters are related through the following equation $M=1 /[1+\ln (n)-\ln (n+m)]$, where $M$ represents the Avrami kinetic parameter. By applying the above-established equation, the average values of parameter $M$ for considered $\mathrm{SiO}_{2} / \mathrm{Ni}$ molar ratios (in respect to particular value of the heating rate used) were calculated. The following average values of $M$ were obtained: $=1.44$ for $\mathrm{SiO}_{2} / \mathrm{Ni}=0.20,=1.55$ for $\mathrm{SiO}_{2} / \mathrm{Ni}=0.80$ and $=1.50$ for $\mathrm{SiO}_{2} / \mathrm{Ni}=$ 
1.15 , respectively. The $M$ value averaged over all molar ratio values amounts ${ }^{\text {overall }}=$ 1.50. The Johnson-Mehl-Avrami (JMA) model is derived from the first principles and hence, its kinetic parameter $(M)$ has a physical significance. The value of $M$ depends on the shape of the nuclei and the dimensionality of their growth, as well as on the rate of their formation (Koga et al., 2013). Based on the above estimated ${ }^{\text {overall }}$ value $(\sim 1.50)$, we can conclude that the reduction process proceeds through the bulk nucleation which is the dominant mechanism, where there is a three-dimensional growth of crystals with polyhedron-like morphology (Fig. 11). Then we can conclude that the initial stage of surface crystallization occurs through a three-dimensional growth of crystals. However, based on the above-presented results, the optimal experimental combination for a highly active hydrogenation catalyst is a molar $\mathrm{SiO}_{2} / \mathrm{Ni}$ ratio of 1.15 , and the low value of the heating rate with $\beta=2{ }^{\circ} \mathrm{C} \mathrm{min}{ }^{-1}$ (for the specified value of the heating rate, the value of SB parameter $m$ is a very similar (Table VII)). It can be pointed out that numerous investigations have shown that metals can diffuse into a $\mathrm{SiO}_{2}$ support (Scott et al., 1983). A metal silicide can be observed at the interfacial region of $\mathrm{SiO}_{2}$ yet at the temperature of $400{ }^{\circ} \mathrm{C}$ (Scott et al., 1983). Namely, in the initial stage, $\mathrm{SiO}_{2}$ can be present as a layer between the metal and the silicon. Upon annealing at a sufficiently high temperature, the metal diffuses through the $\mathrm{SiO}_{2}$ layer to form a silicide. The formation of the silicide gives rise to lateral non-uniformities in the layer such that the barrier to silicon diffusion is significantly lowered, i.e., silicon diffusion, no longer blocked by the $\mathrm{SiO}_{2}$ layer, is facilitated. We may suppose that the higher temperatures lead to diffusion of $\mathrm{Ni}$ to the $\mathrm{Si} / \mathrm{SiO}_{2}$ interface, likely via oxygen vacancies. 
It can be pointed out, that from a quantitative $\mathrm{X}$-ray diffraction analysis of passivated reduced $\mathrm{SiO}_{2} / \mathrm{Ni}$ catalysts, it has been found that the amount of nickel oxide was proportional to the nickel surface area before passivation, indicating that the oxide found was present on the surface of the nickel crystallites and was formed in passivation (Coenen, 1958). Thus, in the non-passivated reduced catalyst no nickel oxide was present and incomplete reduction was located in the silicate foundation structure. In this case, we can expect that the oxide particle, derived from the solution after dehydration, once its reduction is initiated, is reduced completely. Comparing the obtained results for reduced precursors with those of non-reduced, we can note the importance of chemical interaction with the support. However, up to now, we can identify certain features in the non-reduced precursor (Fig. 10), which may be chemical - type of nickel compound- or the physical - pore structure with attendant mass transport limitations. In addition, based on the established data, we may conclude that the results do not indicate a progressive penetration of the reduction front into the catalyst particles so that the distribution of the reduced material seems to be a probably random (Fig. 11). In view of the morphological results (see SEM analyses) no indication of a spherical reaction front penetrating into the catalyst particles (below $10 \mu \mathrm{m}$ (Homma et al., 2005)) to be presented.

\section{Xps Analysis}

The XPS is an experimental technique that is widely used in physico-chemical characterization of the surface of the catalytic material. In the case of nickel catalysts with supports, this method can determine the dispersion of metallic nickel on the basis 
of peak intensities corresponding to the electronic structure of $\mathrm{Ni} 2_{p 3 / 2}$, and based on the position of the peak in the XPS spectrum, we can determine the oxidation number. The catalyst precursors were characterized by XPS in order to know the difference between the nickel catalyst about the interaction of $\mathrm{NiO}$ with the support and the existence state of nickel on the catalyst surface.

The XPS results for Ni/D catalyst precursors with data analyzed transfer (ASCII data) (data in the form of square symbols ( $\square$ ) - DAT), convert fitted XPS data (full black continuous line), metallic $\mathrm{Ni}$ data (symbol $-\mathrm{I}-$ ) and the oxidation state $\mathrm{Ni}^{2+}$ data (full blue continuous line) are shown in Fig. 12.

The binding energy of $\mathrm{Ni} 2_{p 3 / 2}$ for $\mathrm{Ni} / D$ was close to that for pure $\mathrm{NiO}(853.8 \mathrm{eV}$ (Moulder et al., 1978)). Comparing with pure $\mathrm{NiO}$ (Matsumura et al., 2000), the Ni $2_{p 3 / 2}$ binding energy for $\mathrm{Ni} / D$ was $0.7 \mathrm{eV}$ higher, indicating that nickel species mainly existed in the oxidative state, but interacted with $\mathrm{SiO}_{2}$ to some extent. This result corresponded with the results reported by Matsumura et al. (2000), who indicated that the spectra for Ni 2 3/2 could be separated into two Gaussian peaks (Figure 12). However, the observed anti-symmetry of the base Ni $2_{p 3 / 2}$ peak and its shift towards the lower energy values is a characteristic behavior for the spectra of the reduced samples, indicating the presence of nickel in the oxidation state $\mathrm{Ni}^{\circ}$ (metallic nickel $\mathrm{BE}($ bond energy) $=853.5 \mathrm{eV})($ Figure 12). The XPS data for studied samples (including un-reduced and reduced-passivated precursors) are summarized in Table IX. The current table also shows the calculated ratio of $\mathrm{Ni}^{\circ} / \mathrm{Ni}^{2+}$ surface concentrations. 
We can see from Table IX that the nickel is presented in $\mathrm{Ni}^{2+}$ oxidation state on the surface of the un-reduced $\mathrm{Ni} / D$ sample. The bonding energy (BE) value may be attributed to $\mathrm{Ni}^{2+}$ state in the nickel hydro-silicates on the surface of the sample. The reductionpassivation procedure provokes a strong impoverishment of the nickel on the surface of the Ni/D sample (Table IX). The XPS technique allows us to estimate the active phase dispersion on the samples surface, by determination of the active component/support atomic ratio. It is evident that the $\mathrm{Ni} / \mathrm{Si}$ ratio decrease after the reduction-passivation procedure (the reduced $\mathrm{Ni} / D$ sample (Table $\mathbf{I X})$ ). A lower Ni/Si ratio may be explained by the low Ni and the higher Si surface concentrations. Obviously, the important fact that should be emphasized is that the Ni dispersion decreases. The results which are derived on the basis of XPS analysis are in full compliance with predicted kinetic analysis, and the established mechanistic explanation of the entire process.

\section{CONCLUSION}

The kinetic process for the non-isothermal reduction of silica-supported nickel catalyst precursors with different $\mathrm{SiO}_{2} / \mathrm{Ni}$ molar ratios $\left(\mathrm{SiO}_{2} / \mathrm{Ni}=0.20,0.80\right.$ and 1.15) under hydrogen atmosphere was studied. The Kissinger-Akahira-Sunose (KAS) isoconversional method is used to estimate the dependency of the apparent activation energy on the degree of conversion. It was found that for all the molar ratios, the apparent activation energy is practically constant in the conversion range of $0.20 \leq \alpha \leq 0.80$. In the considered conversion range, the following values of the apparent activation energy $\left(E_{a}\right)$ were found: $134.5 \mathrm{~kJ} \mathrm{~mol}^{-1}\left(\mathrm{SiO}_{2} / \mathrm{Ni}=0.20\right), 139.5 \mathrm{~kJ} \mathrm{~mol}^{-1}\left(\mathrm{SiO}_{2} / \mathrm{Ni}=0.80\right)$ and 128.3 
$\mathrm{kJ} \mathrm{mol}^{-1}\left(\mathrm{SiO}_{2} / \mathrm{Ni}=1.15\right)$. Applying the IKP method for the range where $E_{a}$ is independent on $\alpha$ led to the invariant kinetic parameters, which were used for the numerical evaluation of the differential conversion function $\left(f_{\text {inv }}(\alpha)\right)$ for all investigated systems. It was found that the obtained values of the invariant apparent activation energy, $E_{a, i n v}$, are in good agreement with the values of $E_{a}$ calculated by the Kissinger-AkahiraSunose (KAS) isoconversional method for all observed $\mathrm{SiO}_{2} / \mathrm{Ni}$ molar ratios. The calculated values of $E_{a}$ for various $\mathrm{SiO}_{2} / \mathrm{Ni}$ molar ratios correspond to the range of $E_{a}$ values belonging to reduction/oxidation processes attached to the nickel complex compounds.

It was established that the reduction of $\mathrm{Ni}$ catalyst precursors with different $\mathrm{SiO}_{2} / \mathrm{Ni}$ molar ratios is a complex process and can be described by the two-parameter ŠestákBerggren $(\operatorname{SB}(m, n))$ autocatalytic model $\left(f(\alpha)=\alpha^{m}(1-\alpha)^{n}\right)$. It was found that because of the low crystallite size and high surface area of the reduced sample, the surface nuclei initiate the reaction early. Thus, it was found that the reaction is more LangmuirHinshelwood type, as hydrogen dissociates rapidly on the surface nuclei and the dissociated hydrogen reacts with $\mathrm{Ni}-\mathrm{O}$ active system. It was concluded that the reduction process proceeds through the bulk nucleation which is the dominant mechanism, where three-dimensional growth of crystals with polyhedron-like morphology exist. By using a variety of techniques for specimens characterization, it was found that the surface $\mathrm{Ni} / \mathrm{Si}$ ratio decrease after the reduction process. This has been explained by the low $\mathrm{Ni}$ and the higher Si surface concentrations. It has been disclosed that the Ni dispersion decreases. 
Knowledge of the kinetic behavior of the studied system under controlled heating mode, it allows us to carry out a controlled synthesis of Ni particles of desired sizes.

\section{ACKNOWLEDGMENTS}

This investigation was partially supported by the Ministry of Science and Environmental Protection of Serbia, under the Projects 172015 (Dr Bojan Janković, Dr Željko Čupić) and 45001 (Dr Željko Čupić, Dr Dušan Jovanović, and Dr Miroslav Stanković).

\section{SUPPLEMENTARY DATA}

\section{Supplementary files supplied will be published online alongside the electronic} version of the article in Journal Web Page. 
Table I. (Supplementary data) The apparent kinetic parameters for the reduction process of $\mathrm{Ni}$ catalyst precursor synthesized with molar ratio of $\mathrm{SiO}_{2} / \mathrm{Ni}=0.20$ under hydrogen atmosphere, obtained for each kinetic function versus the heating rates

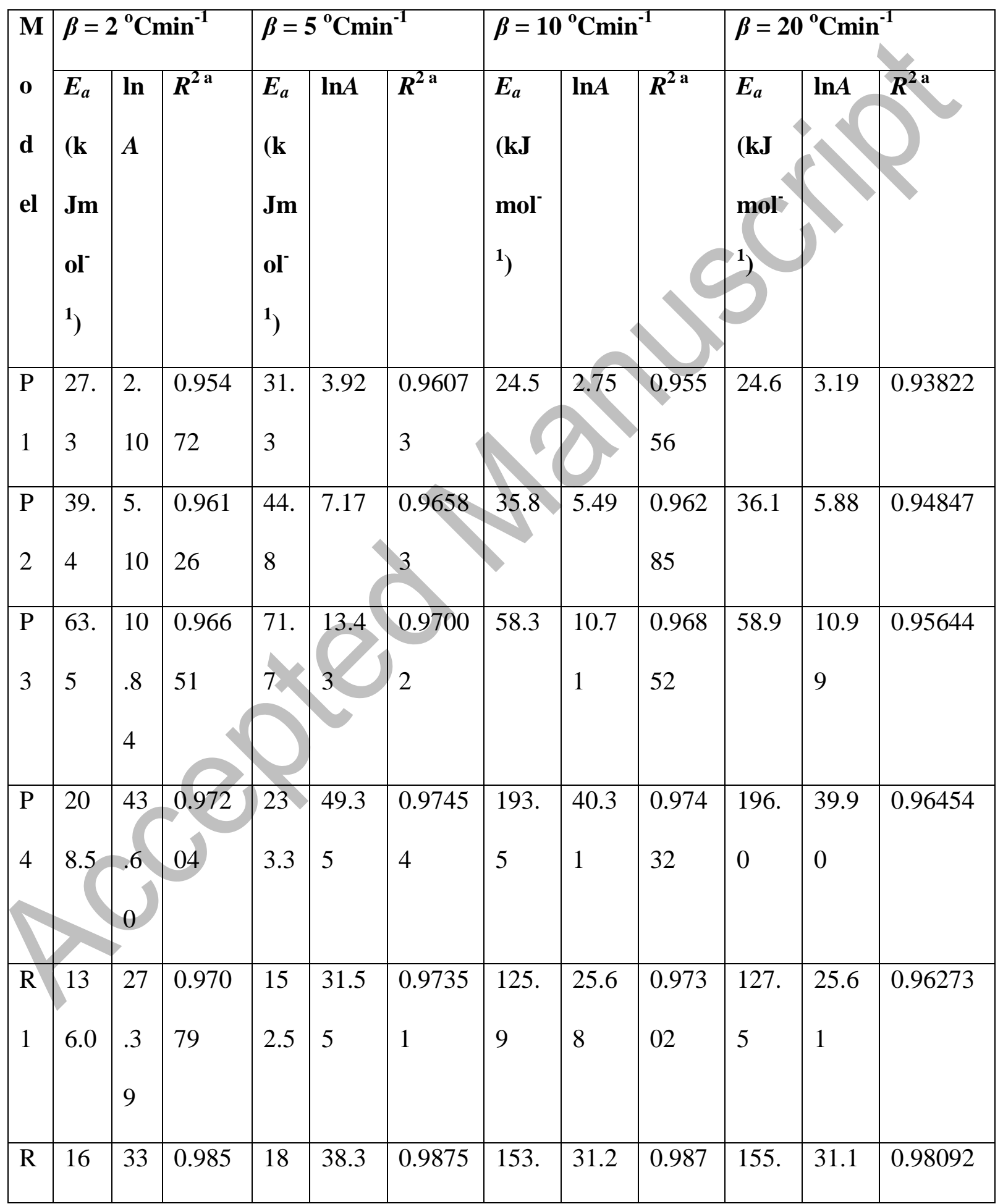




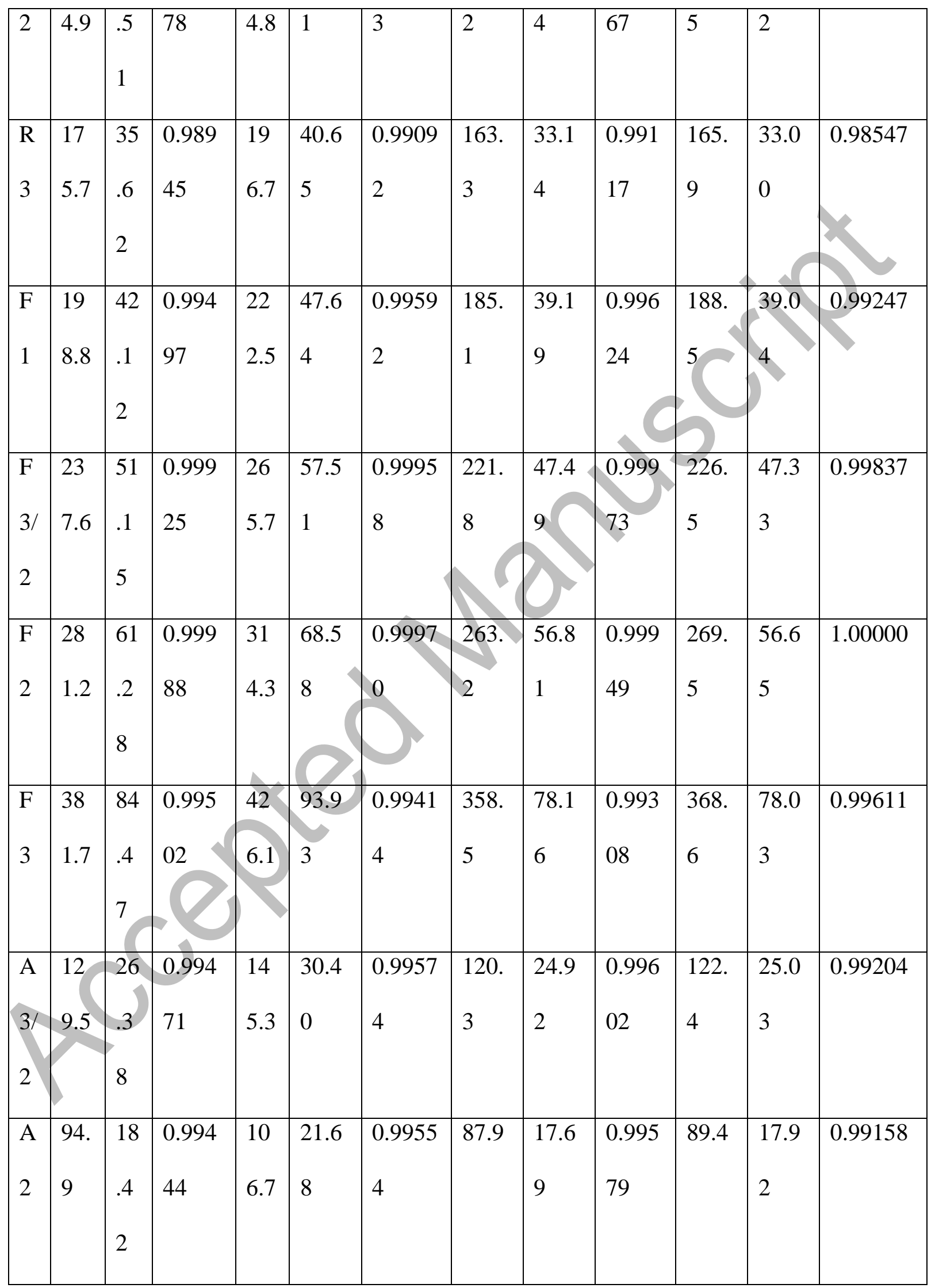




\begin{tabular}{|c|c|c|c|c|c|c|c|c|c|c|c|c|}
\hline 3 & $\begin{array}{l}60 . \\
3\end{array}$ & $\begin{array}{l}10 \\
.3\end{array}$ & $\begin{array}{l}0.993 \\
84\end{array}$ & $\begin{array}{l}68 . \\
1\end{array}$ & $\begin{array}{l}12.8 \\
3\end{array}$ & $\begin{array}{l}0.9951 \\
1\end{array}$ & 55.5 & $\begin{array}{l}10.3 \\
0\end{array}$ & $\begin{array}{l}0.995 \\
26\end{array}$ & 56.4 & $\begin{array}{l}10.6 \\
7\end{array}$ & 0.99053 \\
\hline $\begin{array}{l}\text { A } \\
4\end{array}$ & $\begin{array}{l}43 . \\
0\end{array}$ & $\begin{array}{l}6 . \\
14\end{array}$ & $\begin{array}{l}0.993 \\
13\end{array}$ & $\begin{array}{l}48 . \\
8\end{array}$ & 8.29 & $\begin{array}{l}0.9946 \\
1\end{array}$ & 39.3 & 6.50 & $\begin{array}{l}0.994 \\
64\end{array}$ & 39.9 & 6.93 & 0.98928 \\
\hline $\begin{array}{l}\mathrm{D} \\
1\end{array}$ & $\begin{array}{l}28 \\
1.0\end{array}$ & $\begin{array}{l}59 \\
.6\end{array}$ & $\begin{array}{l}0.972 \\
63\end{array}$ & $\begin{array}{l}31 \\
4.1\end{array}$ & $\begin{array}{l}67.0 \\
1\end{array}$ & $\begin{array}{l}0.9750 \\
3\end{array}$ & $\begin{array}{l}261 . \\
1\end{array}$ & $\begin{array}{l}54.8 \\
1\end{array}$ & $\begin{array}{l}0.974 \\
93\end{array}$ & 264. & & 0.96540 \\
\hline $\begin{array}{l}\mathrm{D} \\
2\end{array}$ & $\begin{array}{l}31 \\
6.7\end{array}$ & $\begin{array}{l}67 \\
.3\end{array}$ & $\begin{array}{l}0.981 \\
80\end{array}$ & $\begin{array}{l}35 \\
4.0\end{array}$ & $\begin{array}{l}75.4 \\
1\end{array}$ & $\begin{array}{l}0.9836 \\
9\end{array}$ & $\begin{array}{l}294 . \\
8\end{array}$ & 61.7 & $\begin{array}{l}0.983 \\
85\end{array}$ & $\begin{array}{l}299 . \\
1\end{array}$ & $\begin{array}{l}60.8 \\
7\end{array}$ & 0.97630 \\
\hline D & $\begin{array}{l}36 \\
0.3\end{array}$ & $\begin{array}{l}75 \\
.8\end{array}$ & $\begin{array}{l}0.990 \\
00\end{array}$ & $\begin{array}{l}40 \\
2.6\end{array}$ & $\begin{array}{l}84.9 \\
4\end{array}$ & 0.9913 & 335. & $\begin{array}{l}69.4 \\
5\end{array}$ & $\begin{array}{l}0.991 \\
67\end{array}$ & $\begin{array}{l}341 . \\
5\end{array}$ & $\begin{array}{l}68.5 \\
6\end{array}$ & 0.98631 \\
\hline D & $\begin{array}{l}33 \\
1.1\end{array}$ & $\begin{array}{l}69 \\
.1\end{array}$ & $\begin{array}{l}0.984 \\
98\end{array}$ & 0.1 & $\begin{array}{l}77.5 \\
5\end{array}$ & $\begin{array}{l}0.9866 \\
8\end{array}$ & $\begin{array}{l}308 . \\
4\end{array}$ & $\begin{array}{l}63.2 \\
7\end{array}$ & $\begin{array}{l}0.986 \\
92\end{array}$ & $\begin{array}{l}313 . \\
1\end{array}$ & $\begin{array}{l}62.4 \\
0\end{array}$ & 0.98016 \\
\hline
\end{tabular}

\footnotetext{
${ }^{\mathrm{a}} R^{2}-$ Adj. R-Square;
} 
Table II. (Supplementary data) The apparent kinetic parameters for the reduction process of $\mathrm{Ni}$ catalyst precursor synthesized with molar ratio of $\mathrm{SiO}_{2} / \mathrm{Ni}=0.80$ under hydrogen atmosphere, obtained for each kinetic function versus the heating rates

\begin{tabular}{|c|c|c|c|c|c|c|c|c|c|c|c|c|}
\hline \multirow{2}{*}{$\begin{array}{l}\text { Mod } \\
\text { el }\end{array}$} & \multicolumn{3}{|c|}{$\beta=2^{\circ} \mathrm{Cmin}^{-1}$} & \multicolumn{3}{|c|}{$\beta=5^{\circ} \mathrm{Cmin}^{-1}$} & \multicolumn{3}{|c|}{$\beta=10^{\circ} \mathrm{Cmin}^{-1}$} & \multicolumn{3}{|c|}{$\beta=20^{\circ} \mathrm{Cmin}^{-1}$} \\
\hline & $\begin{array}{l}E_{a} \\
(\mathrm{kJm} \\
\left.\mathrm{ol}^{-1}\right)\end{array}$ & $\ln A$ & $R^{2 \mathrm{a}}$ & $\begin{array}{l}E_{a} \\
(\mathrm{kJm} \\
\left.\mathrm{ol}^{-1}\right)\end{array}$ & $\ln A$ & $R^{2 \mathrm{a}}$ & $\begin{array}{l}E_{a} \\
(\mathrm{kJm} \\
\left.\mathrm{ol}^{-1}\right)\end{array}$ & $\ln A$ & $\boldsymbol{R}^{2}$ & $\begin{array}{l}E_{a} \\
(\mathrm{kJm} \\
\left.\mathrm{ol}^{-1}\right)\end{array}$ & $\ln A$ & $R^{2 \mathrm{a}}$ \\
\hline $\mathrm{P} 1$ & 40.6 & 5.53 & $\begin{array}{l}0.972 \\
67\end{array}$ & 30.8 & 3.82 & $\begin{array}{l}0.961 \\
52\end{array}$ & 36.3 & 5.73 & $\begin{array}{l}0.973 \\
75\end{array}$ & 31.9 & 5.01 & $\begin{array}{l}0.955 \\
20\end{array}$ \\
\hline $\mathrm{P} 2$ & 57.1 & 9.50 & $\begin{array}{l}0.975 \\
44\end{array}$ & 44.1 & 7.04 & 0.966 & 51.4 & 9.30 & $\begin{array}{l}0.976 \\
80\end{array}$ & 45.7 & 8.19 & $\begin{array}{l}0.961 \\
16\end{array}$ \\
\hline $\mathrm{P} 3$ & 90.1 & $\begin{array}{l}17.2 \\
3\end{array}$ & $\begin{array}{l}0.977 \\
83\end{array}$ & 70.7 & 13.2 & $\begin{array}{l}0.970 \\
73\end{array}$ & 81.8 & $\begin{array}{l}16.2 \\
1\end{array}$ & $\begin{array}{l}0.979 \\
37\end{array}$ & 73.3 & $\begin{array}{l}14.3 \\
2\end{array}$ & $\begin{array}{l}0.966 \\
03\end{array}$ \\
\hline P4 & 288.1 & $\begin{array}{l}62.0 \\
2\end{array}$ & $\begin{array}{l}0.980 \\
51\end{array}$ & 230.3 & $\begin{array}{l}48.8 \\
2\end{array}$ & $\begin{array}{l}0.975 \\
19\end{array}$ & 263.7 & $\begin{array}{l}56.0 \\
8\end{array}$ & $\begin{array}{l}0.982 \\
19\end{array}$ & 239.0 & $\begin{array}{l}49.3 \\
9\end{array}$ & $\begin{array}{l}0.971 \\
25\end{array}$ \\
\hline $\mathrm{R} 1$ & & $\begin{array}{l}39.7 \\
8\end{array}$ & $\begin{array}{l}0.979 \\
88\end{array}$ & 150.5 & $\begin{array}{l}31.2 \\
0\end{array}$ & $\begin{array}{l}0.974 \\
17\end{array}$ & 172.7 & $\begin{array}{l}36.3 \\
1\end{array}$ & $\begin{array}{l}0.981 \\
54\end{array}$ & 156.2 & $\begin{array}{l}32.0 \\
2\end{array}$ & $\begin{array}{l}0.970 \\
06\end{array}$ \\
\hline $\mathrm{R} 2$ & 227.9 & $\begin{array}{l}48.1 \\
5\end{array}$ & $\begin{array}{l}0.992 \\
05\end{array}$ & 182.7 & $\begin{array}{l}37.9 \\
6\end{array}$ & $\begin{array}{l}0.988 \\
56\end{array}$ & 206.3 & $\begin{array}{l}43.2 \\
5\end{array}$ & $\begin{array}{l}0.992 \\
53\end{array}$ & 190.9 & $\begin{array}{l}38.9 \\
7\end{array}$ & $\begin{array}{l}0.986 \\
17\end{array}$ \\
\hline R3 & 242.2 & $\begin{array}{l}51.0 \\
9\end{array}$ & $\begin{array}{l}0.994 \\
79\end{array}$ & 194.7 & $\begin{array}{l}40.3 \\
1\end{array}$ & $\begin{array}{l}0.991 \\
96\end{array}$ & 218.7 & $\begin{array}{l}45.6 \\
5\end{array}$ & $\begin{array}{l}0.995 \\
02\end{array}$ & 203.9 & $\begin{array}{l}41.4 \\
0\end{array}$ & $\begin{array}{l}0.990 \\
04\end{array}$ \\
\hline $\mathrm{F} 1$ & 273.2 & 59.3 & 0.998 & 220.5 & 47.3 & 0.996 & 245.3 & 52.7 & 0.998 & 231.9 & 48.6 & 0.995 \\
\hline
\end{tabular}




\begin{tabular}{|c|c|c|c|c|c|c|c|c|c|c|c|c|}
\hline & & 8 & 44 & & 5 & 82 & & 5 & 41 & & 3 & 69 \\
\hline $\mathrm{F} 3 / 2$ & 325.4 & $\begin{array}{l}71.4 \\
5\end{array}$ & $\begin{array}{l}0.999 \\
92\end{array}$ & 264.0 & $\begin{array}{l}57.3 \\
3\end{array}$ & $\begin{array}{l}0.999 \\
87\end{array}$ & 289.6 & $\begin{array}{l}62.7 \\
5\end{array}$ & $\begin{array}{l}0.999 \\
97\end{array}$ & 279.4 & $\begin{array}{l}58.9 \\
5\end{array}$ & $\begin{array}{l}0.999 \\
65\end{array}$ \\
\hline $\bar{F} 2$ & 384.1 & $\begin{array}{l}85.0 \\
1\end{array}$ & $\begin{array}{l}0.998 \\
99\end{array}$ & 313.1 & $\begin{array}{l}68.5 \\
4\end{array}$ & $\begin{array}{l}0.999 \\
09\end{array}$ & 339.4 & $\begin{array}{l}73.9 \\
0\end{array}$ & $\begin{array}{l}0.998 \\
89\end{array}$ & 333.2 & $\begin{array}{l}70.5 \\
9\end{array}$ & $\begin{array}{l}0.999 \\
49\end{array}$ \\
\hline $\bar{F} 3$ & 519.3 & $\begin{array}{l}116 . \\
10\end{array}$ & $\begin{array}{l}0.988 \\
07\end{array}$ & 426.3 & $\begin{array}{l}94.2 \\
7\end{array}$ & $\begin{array}{l}0.991 \\
55\end{array}$ & 453.2 & $\begin{array}{l}99.3 \\
7\end{array}$ & $\begin{array}{l}0.989 \\
78\end{array}$ & 457.3 & $\begin{array}{l}97.3 \\
6\end{array}$ & $\begin{array}{l}0.992 \\
77\end{array}$ \\
\hline $\mathrm{A} 3 / 2$ & 179.2 & $\begin{array}{l}38.0 \\
1\end{array}$ & $\begin{array}{l}0.998 \\
38\end{array}$ & 144.0 & $\begin{array}{l}30.2 \\
1\end{array}$ & $\begin{array}{l}0.996 \\
67\end{array}$ & 160.4 & 34.0 & $\begin{array}{l}0.998 \\
34\end{array}$ & 151.4 & $\begin{array}{l}31.5 \\
0\end{array}$ & $\begin{array}{l}0.995 \\
50\end{array}$ \\
\hline A2 & 132.2 & $\begin{array}{l}27.2 \\
3\end{array}$ & $\begin{array}{l}0.998 \\
32\end{array}$ & 105.7 & $\begin{array}{l}21.5 \\
4\end{array}$ & 0.996 & 118.0 & $\begin{array}{l}24.6 \\
3\end{array}$ & $\begin{array}{l}0.998 \\
27\end{array}$ & 111.2 & $\begin{array}{l}22.8 \\
4\end{array}$ & $\begin{array}{l}0.995 \\
29\end{array}$ \\
\hline A3 & 85.1 & $\begin{array}{l}16.3 \\
1\end{array}$ & $\begin{array}{l}0.998 \\
19\end{array}$ & 67.4 & $\begin{array}{l}12.7 \\
3\end{array}$ & $\begin{array}{l}0.996 \\
17\end{array}$ & 75.6 & $\begin{array}{l}15.0 \\
5\end{array}$ & $\begin{array}{l}0.998 \\
11\end{array}$ & 70.9 & $\begin{array}{l}14.0 \\
4\end{array}$ & $\begin{array}{l}0.994 \\
82\end{array}$ \\
\hline A4 & 61.6 & $\begin{array}{l}10.7 \\
5\end{array}$ & 0.998 & & 8.21 & $\begin{array}{l}0.995 \\
77\end{array}$ & 54.4 & $\begin{array}{l}10.1 \\
5\end{array}$ & $\begin{array}{l}0.997 \\
92\end{array}$ & 50.8 & 9.53 & $\begin{array}{l}0.994 \\
29\end{array}$ \\
\hline D1 & 387.1 & 84.1 & $\begin{array}{l}0.980 \\
81\end{array}$ & 310.1 & 66.3 & $\begin{array}{l}0.975 \\
68\end{array}$ & 354.7 & $\begin{array}{l}75.7 \\
3\end{array}$ & $\begin{array}{l}0.982 \\
50\end{array}$ & 321.9 & $\begin{array}{l}66.6 \\
4\end{array}$ & $\begin{array}{l}0.971 \\
82\end{array}$ \\
\hline D2 & 434.9 & $\begin{array}{l}94.5 \\
1\end{array}$ & $\begin{array}{l}0.988 \\
53\end{array}$ & 349.7 & 74.7 & $\begin{array}{l}0.984 \\
58\end{array}$ & 396.4 & $\begin{array}{l}84.4 \\
1\end{array}$ & $\begin{array}{l}0.989 \\
45\end{array}$ & 364.6 & $\begin{array}{l}75.2 \\
3\end{array}$ & $\begin{array}{l}0.981 \\
71\end{array}$ \\
\hline D3 & 493.4 & $\begin{array}{l}106 . \\
48\end{array}$ & $\begin{array}{l}0.994 \\
98\end{array}$ & 398.4 & 84.3 & $\begin{array}{l}0.992 \\
34\end{array}$ & 446.6 & $\begin{array}{l}94.1 \\
7\end{array}$ & $\begin{array}{l}0.995 \\
24\end{array}$ & 417.3 & $\begin{array}{l}85.1 \\
3\end{array}$ & $\begin{array}{l}0.990 \\
51\end{array}$ \\
\hline D4 & 454.3 & $\begin{array}{l}97.4 \\
6\end{array}$ & $\begin{array}{l}0.991 \\
12\end{array}$ & 365.8 & 76.9 & $\begin{array}{l}0.987 \\
64\end{array}$ & 413.0 & $\begin{array}{l}86.6 \\
3\end{array}$ & $\begin{array}{l}0.991 \\
76\end{array}$ & 382.0 & $\begin{array}{l}77.4 \\
9\end{array}$ & $\begin{array}{l}0.985 \\
16\end{array}$ \\
\hline
\end{tabular}


${ }^{\mathrm{a}} R^{2}-$ Adj. R-Square;

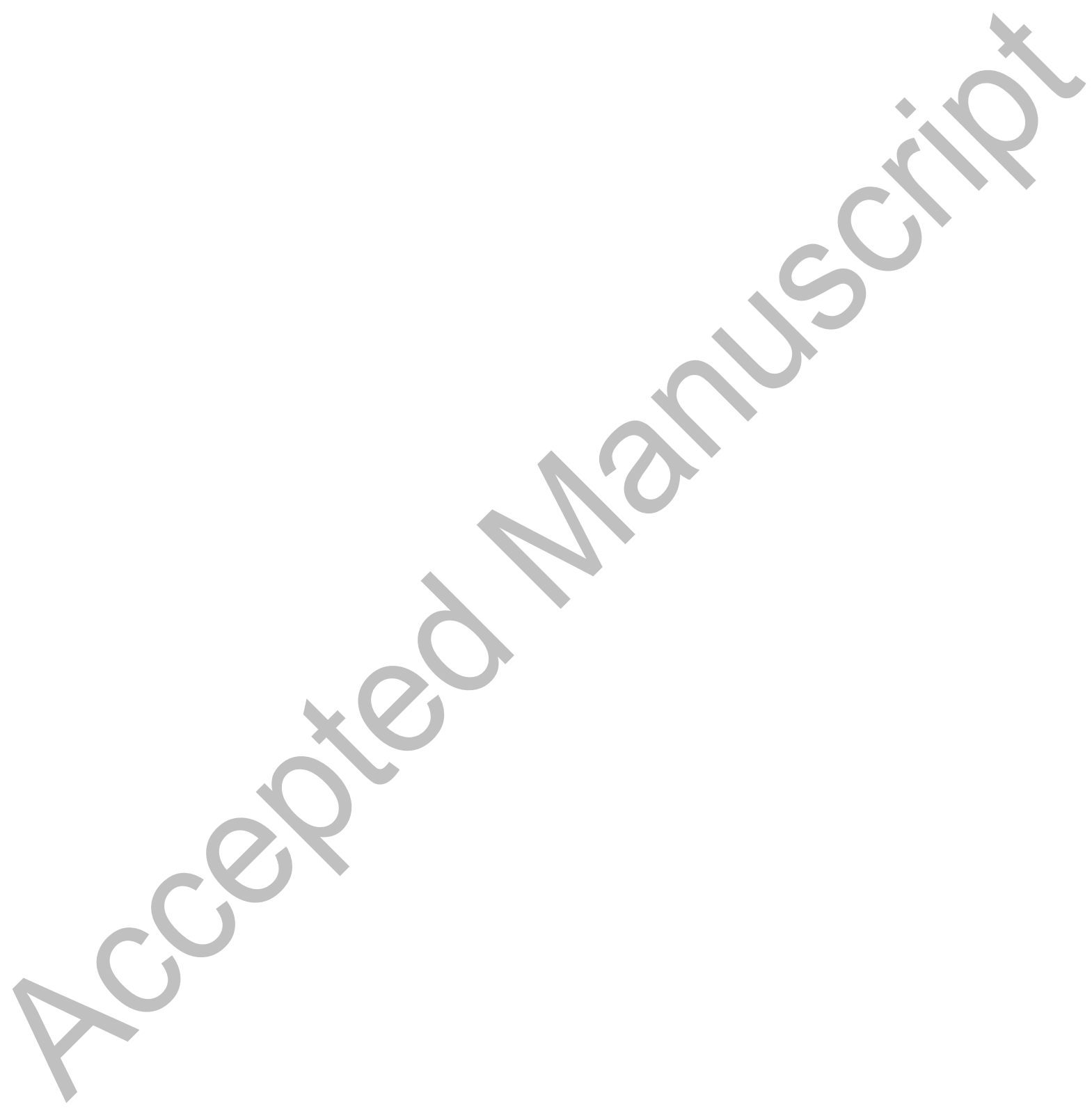


Table III. (Supplementary data) The apparent kinetic parameters for the reduction process of $\mathrm{Ni}$ catalyst precursor synthesized with molar ratio of $\mathrm{SiO}_{2} / \mathrm{Ni}=1.15$ under hydrogen atmosphere, obtained for each kinetic function versus the heating rates

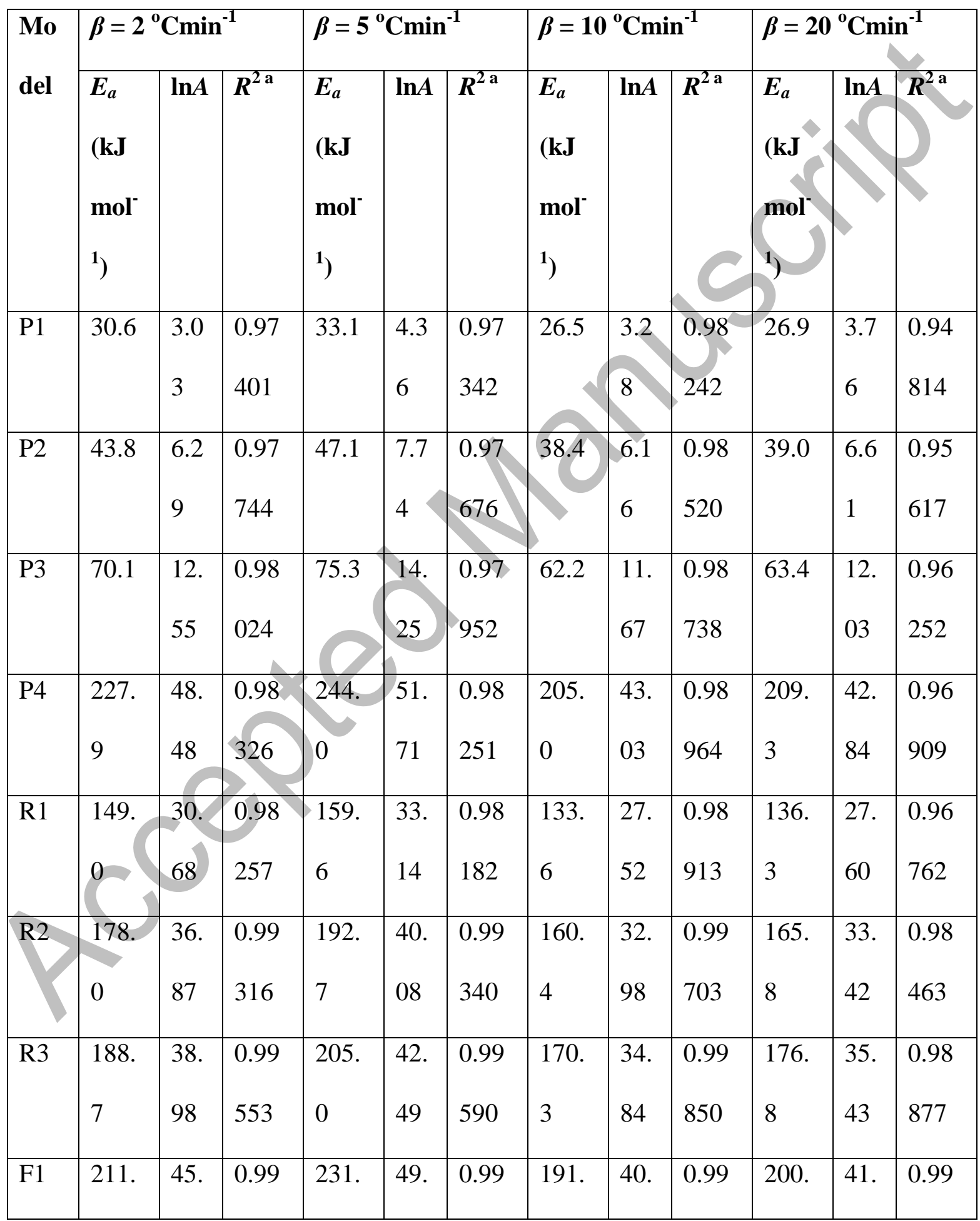




\begin{tabular}{|c|c|c|c|c|c|c|c|c|c|c|c|c|}
\hline & 6 & 48 & 868 & 5 & 65 & 904 & 5 & 77 & 990 & 6 & 73 & 492 \\
\hline $\mathrm{F} 3 / 2$ & $\begin{array}{l}249 . \\
9\end{array}$ & $\begin{array}{l}54 . \\
46\end{array}$ & $\begin{array}{l}0.99 \\
993\end{array}$ & $\begin{array}{l}276 . \\
0\end{array}$ & $\begin{array}{l}59 . \\
81\end{array}$ & $\begin{array}{l}0.99 \\
970\end{array}$ & $\begin{array}{l}227 . \\
0\end{array}$ & $\begin{array}{l}48 . \\
81\end{array}$ & $\begin{array}{l}0.99 \\
873\end{array}$ & $\begin{array}{l}240 . \\
6\end{array}$ & $\begin{array}{l}50 . \\
46\end{array}$ & $\begin{array}{l}0.99 \\
944\end{array}$ \\
\hline $\bar{F} 2$ & $\begin{array}{l}292 . \\
8\end{array}$ & $\begin{array}{l}64 . \\
47\end{array}$ & $\begin{array}{l}0.99 \\
803\end{array}$ & $\begin{array}{l}326 . \\
2\end{array}$ & $\begin{array}{l}71 . \\
21\end{array}$ & $\begin{array}{l}0.99 \\
677\end{array}$ & $\begin{array}{l}266 . \\
7\end{array}$ & $\begin{array}{l}57 . \\
78\end{array}$ & $\begin{array}{l}0.99 \\
472\end{array}$ & $\begin{array}{l}285 . \\
9\end{array}$ & $\begin{array}{l}60 . \\
29\end{array}$ & $\begin{array}{l}0.99 \\
966\end{array}$ \\
\hline$\overline{F 3}$ & $\begin{array}{l}390 . \\
9\end{array}$ & $\begin{array}{l}87 . \\
31\end{array}$ & $\begin{array}{l}0.98 \\
925\end{array}$ & $\begin{array}{l}441 . \\
7\end{array}$ & $\begin{array}{l}97 . \\
40\end{array}$ & $\begin{array}{l}0.98 \\
573\end{array}$ & $\begin{array}{l}357 . \\
6\end{array}$ & $\begin{array}{l}78 . \\
25\end{array}$ & $\begin{array}{l}0.98 \\
279\end{array}$ & 390. & 86 & $\begin{array}{l}0.99 \\
319\end{array}$ \\
\hline $\begin{array}{l}\text { A3/ } \\
2\end{array}$ & $\begin{array}{l}138 . \\
1\end{array}$ & $\begin{array}{l}28 . \\
65\end{array}$ & $\begin{array}{l}0.99 \\
861\end{array}$ & $\begin{array}{l}151 . \\
3\end{array}$ & $\begin{array}{l}31 . \\
75\end{array}$ & $\begin{array}{l}0.99 \\
899\end{array}$ & $\begin{array}{l}124 . \\
6\end{array}$ & 99 & $\begin{array}{l}0.99 \\
990\end{array}$ & $\begin{array}{l}130 . \\
5\end{array}$ & $\begin{array}{l}26 . \\
84\end{array}$ & $\begin{array}{l}0.99 \\
464\end{array}$ \\
\hline A2 & $\begin{array}{l}101 . \\
4\end{array}$ & $\begin{array}{l}20 . \\
14\end{array}$ & $\begin{array}{l}0.99 \\
854\end{array}$ & $\begin{array}{l}111 . \\
2\end{array}$ & $\begin{array}{l}22 . \\
71\end{array}$ & $\begin{array}{l}0.99 \\
895\end{array}$ & 91.1 & 18. & $\begin{array}{l}0.99 \\
989\end{array}$ & 95.5 & $\begin{array}{l}19 . \\
30\end{array}$ & $\begin{array}{l}0.99 \\
435\end{array}$ \\
\hline A3 & 64.6 & $\begin{array}{l}11 . \\
49\end{array}$ & $\begin{array}{l}0.99 \\
838\end{array}$ & 71.1 & $\begin{array}{l}13 . \\
52\end{array}$ & $\begin{array}{l}0.99 \\
884\end{array}$ & 57.7 & $\begin{array}{l}10 . \\
86\end{array}$ & $\begin{array}{l}0.99 \\
987\end{array}$ & 60.5 & $\begin{array}{l}11 . \\
62\end{array}$ & $\begin{array}{l}0.99 \\
368\end{array}$ \\
\hline A4 & 46.3 & $\begin{array}{l}7.0 \\
6\end{array}$ & $\begin{array}{l}0.99 \\
820\end{array}$ & & 8.8 & $\begin{array}{l}0.99 \\
872\end{array}$ & 41.0 & $\begin{array}{l}6.9 \\
3\end{array}$ & $\begin{array}{l}0.99 \\
985\end{array}$ & 42.9 & $\begin{array}{l}7.6 \\
7\end{array}$ & $\begin{array}{l}0.99 \\
290\end{array}$ \\
\hline D1 & $\begin{array}{l}306 . \\
8\end{array}$ & $\begin{array}{c}66 . \\
15\end{array}$ & 359 & 328. & $\begin{array}{l}70 . \\
14\end{array}$ & $\begin{array}{l}0.99 \\
284\end{array}$ & $\begin{array}{l}276 . \\
5\end{array}$ & $\begin{array}{l}58 . \\
41\end{array}$ & $\begin{array}{l}0.98 \\
988\end{array}$ & $\begin{array}{l}282 . \\
3\end{array}$ & $\begin{array}{l}57 . \\
95\end{array}$ & $\begin{array}{l}0.96 \\
979\end{array}$ \\
\hline D2 & 342. & $\begin{array}{l}73 . \\
89\end{array}$ & $\begin{array}{l}0.99 \\
026\end{array}$ & $\begin{array}{l}369 . \\
2\end{array}$ & $\begin{array}{l}78 . \\
76\end{array}$ & $\begin{array}{l}0.99 \\
016\end{array}$ & $\begin{array}{l}309 . \\
7\end{array}$ & $\begin{array}{l}65 . \\
25\end{array}$ & $\begin{array}{l}0.99 \\
496\end{array}$ & $\begin{array}{l}318 . \\
6\end{array}$ & $\begin{array}{l}65 . \\
16\end{array}$ & $\begin{array}{l}0.98 \\
012\end{array}$ \\
\hline D3 & $\begin{array}{l}386 . \\
3\end{array}$ & $\begin{array}{l}82 . \\
52\end{array}$ & $\begin{array}{l}0.99 \\
575\end{array}$ & $\begin{array}{l}419 . \\
1\end{array}$ & $\begin{array}{l}88 . \\
58\end{array}$ & $\begin{array}{l}0.99 \\
609\end{array}$ & $\begin{array}{l}349 . \\
9\end{array}$ & $\begin{array}{l}72 . \\
80\end{array}$ & $\begin{array}{l}0.99 \\
859\end{array}$ & $\begin{array}{l}363 . \\
2\end{array}$ & $\begin{array}{l}73 . \\
33\end{array}$ & $\begin{array}{l}0.98 \\
938\end{array}$ \\
\hline D4 & $\begin{array}{l}357 . \\
3\end{array}$ & $\begin{array}{l}75 . \\
74\end{array}$ & $\begin{array}{l}0.99 \\
246\end{array}$ & $\begin{array}{l}385 . \\
7\end{array}$ & $\begin{array}{l}81 . \\
00\end{array}$ & $\begin{array}{l}0.99 \\
257\end{array}$ & $\begin{array}{l}323 . \\
0\end{array}$ & $\begin{array}{l}66 . \\
74\end{array}$ & $\begin{array}{l}0.99 \\
650\end{array}$ & $\begin{array}{l}333 . \\
3\end{array}$ & $\begin{array}{l}66 . \\
85\end{array}$ & $\begin{array}{l}0.98 \\
373\end{array}$ \\
\hline
\end{tabular}


${ }^{\mathrm{a}} R^{2}-$ Adj. R-Square;

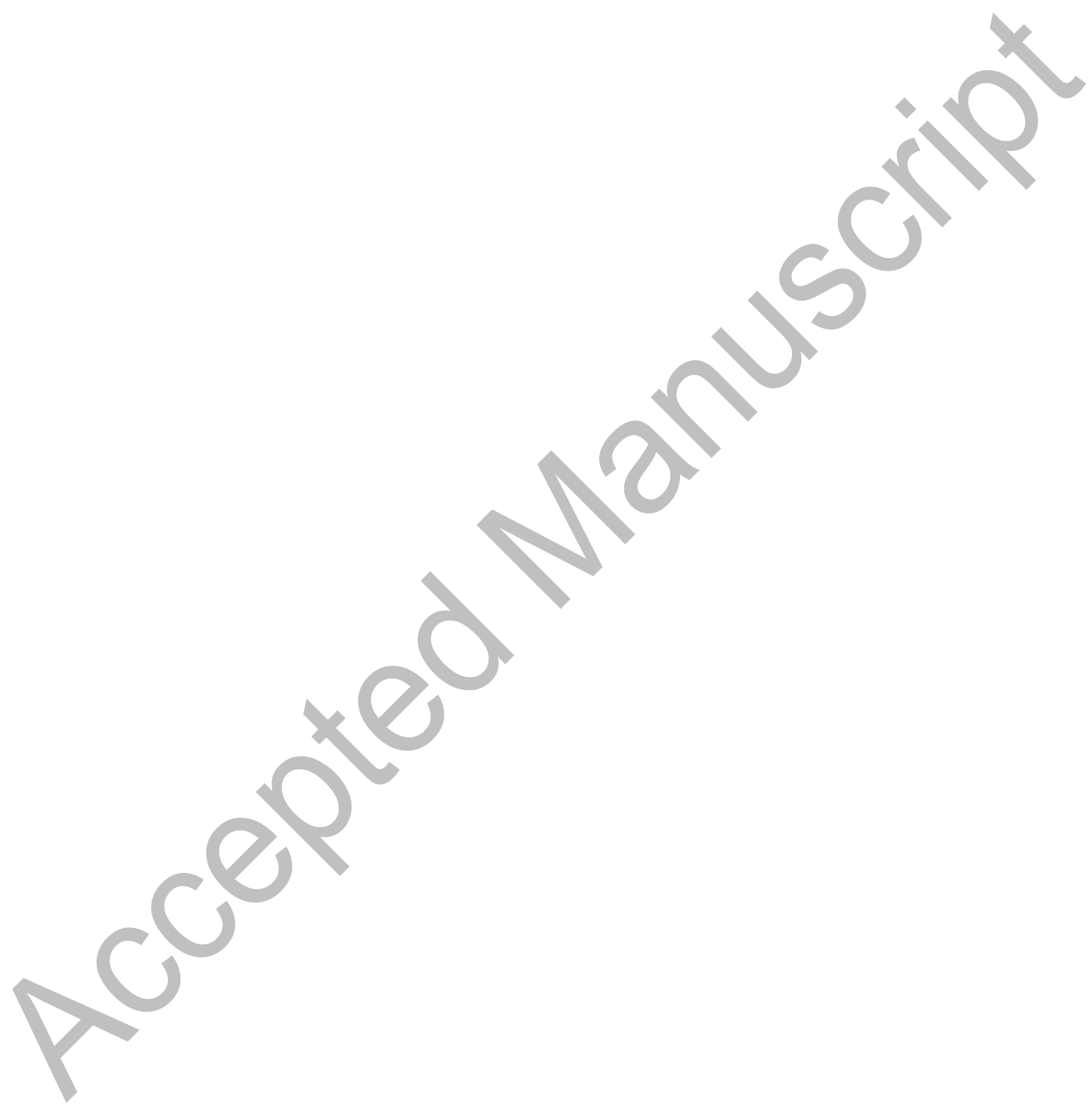




\section{REFERENCES}

Akahira, T., Sunose, T. (1971). Joint convention of four electrical institutes, Research Reports of Chiba Institute of Technology, 16, 22-31.

Avrami, M. (1939). Kinetics of phase change. I General theory, Journal of Chemical Physics, 7, 1103-1113.

Avrami, M. (1940). Kinetics of phase change. II Transformation-time relations for random distribution of nuclei, Journal of Chemical Physics, 8, 212-224.

Avrami, M. (1941). Kinetics of phase change. III Granulation, phase change and microstructures, Journal of Chemical Physics, 9, 177-184.

Bartholomew, C.H. (1990). Hydrogen adsorption on supported cobalt, iron and nickel. Catalysis Letters, 7, 27-52.

Bartholomew, C.H., Pannell, R.B. (1980). The stoichiometry of hydrogen and carbon monoxide chemisorption on alumina- and silica-supported nickel. Journal of Catalysis, 65, 390-401.

Bhatia, S., Beltramini, I., Do, D.D. (1990). Temperature-programmed analysis and its applications in catalytic systems, Catalysis Today, 7, 309-438.

Bhering, D.L., Nele, M., Pinto, J.C., Salim, V.M.M. (2002). Preparation of high loading silica-supported nickel catalyst: analysis of the reduction step, Applied Catalysis A:

General, 234, 55-64.

Brown, M.E., Dollimore, D., Galwey, A.K. (1980). Reaction In The Solid State, In Comprehensive Chemical Kinetics, Bamford, C.H., Tipper, C.F.H. (Eds.), Vol. 22, Elsevier, Amsterdam, pp. 340-341. 
Brown, M.E. (2001). Introduction to Thermal Analysis: Techniques and Applications, 2nd Ed., Kluwer Academic Publishers, Dordrecht, The Netherlands, pp. 21-43. Budrugeac, P., Segal, E., Pérez-Maqueda, L.A., Criado, J.M. (2004). The use of the IKP method for evaluating the kinetic parameters and the conversion function of the thermal dehydrochlorination of PVC from non-isothermal data, Polymer Degradation and Stability, 84, 311-320.

Bulánek, R., Čičmanec, P. (2008). Kinetics of reduction of Cu ions in MFI zeolite investigated by $\mathrm{H}_{2}$-TPR method, Collection of Czechoslovak Chemical Communications, 73, 1132-1148.

Butler, M.A., James, P.F., Jackson, J.D. (1996). An emulsion method for producing fine, low density, high surface area silica powder from alkoxides, Journal of Materials Science, 31, 1675-1680.

Che, M., Cheng, Z.X., Louis, C. (1995). Nucleation and particle growth processes involved in the preparation of silica-supported nickel materials by a two-step procedure, Journal of American Chemical Society, 117, 2008-2018.

Coats, A.W., Redfern, J.P. (1964). Kinetic parameters from thermogravimetric data, Nature, 201, 68-69.

Coenen, J.W.E. (1958). Onderzoek van technische nikkelkatalysatoren op dragger.

Doctoral Thesis from the Technische Hogeschool Delft, Delft, The Netherlands, pp. 144156.

Coenen, J.W.E., Linsen, B.G. (1970). Physical and chemical aspects of adsorbents and catalysts. Academic Press, London, UK, pp. 25-32. 
Criado, J.M., Málek, J., Ortega, A. (1989). Applicability of the master plots kinetic analysis of non-isothermal data, Thermochimica Acta, 147, 377-385.

Cvetanović, R.J., Amenomiya, Y. (1972). Temperature programmed desorption technique for investigation of practical catalysts, Catalysis Reviews, 6, 21-48.

Dalmai-Imelik, G., Leclercq, C., Maubert-Muguet, A. (1976). Study by electron microscopy and electron diffraction of formation of nickel epitaxially grown catalysts, Journal of Solid State Chemistry, 16, 129-139.

Delmon, B., Roman, A. (1973). Kinetic study of the reduction of nickel oxide near its antiferro-magnetic-paramagnetic transition. Influence of the magnetic structure of the reactant on the kinetics of nucleus formation on its surface, Journal of the Chemical Society, Faraday Transactions 1: Physical Chemistry in Condensed Phases, 69, 941-949.

Delmon, B. (1979). Preparation of Catalysts II, In: Scientific Bases for the Preparation of Heterogeneous Catalysts, Grange, P., Jacobs, P., Poncelet, G. (Eds.), Elsevier, Amsterdam, The Netherlands, pp. 51-59.

Deraz, N.M., Selim, M.M., Ramadan, M. (2009). Processing and properties of nanocrystalline $\mathrm{Ni}$ and $\mathrm{NiO}$ catalysts, Materials Chemistry and Physics, 113, 269-275.

Falconer, J.L., Schwarz, J.A. (1983). Temperature-programmed desorption and reaction: Applications to supported catalysts, Catalysis Reviews: Science and Engineering, 25, $141-227$.

Fierro, J.L.G., Peña, M.A. (2005). Supported Metals in the Production of Hydrogen. In: Supported Metals in Catalysis. 1st Ed., Anderson, J.A., Fernández García, M. (Eds.), Imperial College Press, World Scientific Publishing Co. Pte. Ltd., London, UK, pp. 229255. 
Geus, J.W. (1988). Energetics of Hydrogen Adsorption on Porous and Supported Metals. In: Hydrogen Effects in Catalysis: Fundamentals and Practical Applications. 1st Ed., Paál, Z., Menon, P.G., Editors, Marcel Dekker, Inc., New York, USA, pp. 85-117. Gil, A., Díaz, A., Gandía, L.M., Montes, M. (1994). Influence of the preparation method and the nature of the support on the stability of nickel catalysts, Applied Catalysis A: General, 109, 167-179.

González-Marcos, M.P., Gutiérrez-Ortiz, J., González-Ortiz de Elguea, C., Delgado, J., González-Velasco, J.R. (1997). Nickel on silica systems. Surface features and their relationship with support, preparation procedure and nickel content, Applied Catalysis A: General, 162, 269-280.

Grange, P., Charcosset, H., Trambouze, Y. (1969). Etude de l'incorporation de l'oxyde de cuivre dans le reseau de l'oxyde de nickel par traitement thermique, Journal of Thermal Analysis and Calorimetry, 1, 311-317.

Gronchi, P., Kaddouri, A., Centola, P., Del Rosso, R. (2003). Synthesis of nickel supported catalysts for hydrogen production by sol-gel method, Journal of Sol-Gel Science and Technology, 26, 843-846.

Hoang-Van, C., Kachaya, Y., Teichner, S.J., Arnaud, Y., Dalmon, J.A. (1989). Characterization of nickel catalysts by chemisorption techniques, X-ray diffraction and magnetic measurements. Effects of support, precursor and hydrogen pretreatment, Applied Catalysis, 46, 281-296.

Homma, S., Ogata, S., Koga, J., Matsumoto, S. (2005). Gas-solid reaction model for a shrinking spherical particle with unreacted shrinking core, Chemical Engineering Science, 60, 4971-4980. 
Hurst, N.W., Gentry, S.J., Jones, A., McNicol, B.D. (1982). Temperature-programmed reduction, Catalysis Reviews: Science and Engineering, 24, 233-309.

Jackson, S.D., Willis, J., Kelly, G.J., McLellan, G.D., Webb, G., Mather, S., Moyes, R.B., Simpson, S., Wells, P.B., Whyman, R. (1999). Supported nickel catalysts: Preparation and characterization of alumina-, molybdena-, and silica-supported nickel, and the identification of reactive oxygen on these catalysts by exchange with isotopically lebelled carbon dioxide. Physical Chemistry Chemical Physics, 1, 2573-2580. Janković, B., Adnađević, B., Mentus, S. (2008). The kinetic study of temperatureprogrammed reduction of nickel oxide in hydrogen atmosphere. Chemical Engineering Science, 63, 567-575.

Johnson, W.A., Mehl, R.F. (1939). Reaction kinetics in processes of nucleation and growth, Trans AIME Papers, 135, 416-458.

Jovanović, D., Radović, R., Mareš, Lj., Stanković, M., Marković, B. (1998). Nickel hydrogenation catalyst for tallow hydrogenation and for the selective hydrogenation of sunflower seed oil and soybean oil, Catalysis Today, 43, 21-28.

Kapteijn, F., Moulijn, J.A., Tarfaoui, A. (1999). Catalyst characterization and mimicking pre-treatment procedures by temperature-programmed techniques, In Catalysis: An Integrated Approach, Vol. 123 of Stud. Surf. Sci. Catal., Elsevier, Amsterdam, pp. 525541.

Kissinger, H.E. (1957). Reaction kinetics in differential thermal analysis, Analytical Chemistry, 29, 1702-1706.

Koga, N., Šesták, J. (1991). Further aspects of the kinetic compensation effect, Journal of Thermal Analysis and Calorimetry, 37, 1103-1108. 
Koga, N., Šesták, J., Šimon, P. (2013). Some Fundamental and Historical Aspects of Phenomenological Kinetics in the Solid State Studied by Thermal Analysis, In: Thermal Analysis of Micro, Nano- and Non-Crystalline Materials. 1st Ed., Šesták, J., Šimon, P. (Eds.), Springer Dordrecht, Heidelberg, New York, London, USA/UK, pp. 1-29. Koga, N., Málek, J. (1996). Accommodation of the actual solid-state process in the kinetic model function. Part 2. Applicability of the empirical kinetic model function to diffusion-controlled reactions, Thermochimica Acta, 282-283, 69-80.

Lemaitre, J.L. (1984). Temperature-programmed methods, In Characterization of Heterogeneous Catalysts, Delannay, F. (Ed.), Marcel Dekker, Inc., New York, pp. 29-70. Lesnikovich, A.I., Levchik, S.V. (1983). A method of finding invariant values of kinetic parameters, Journal of Thermal Analysis and Calorimetry, 27, 89-93.

Lesnikovich, A.I., Levchik, S.V. (1985). Isoparametric kinetic relations for chemical transformations in condensed substances (Analytical survey). II. Reactions involving the participation of solid substances, Journal of Thermal Analysis and Calorimetry, 30, 677702.

Liu, Y., Chen, J., Zhang, J. (2007). Effects on the supports on activity of supported nickel catalysts for hydrogenation of $m$-dinitrobenzene to $m$-phenylenediamine, Chinese Journal of Chemical Engineering, 15, 63-67.

L'vov, B.V., Galwey, A.K. (2012). The mechanism and kinetics of $\mathrm{NiO}$ reduction by hydrogen. Thermochemical approach, Journal of Thermal Analysis and Calorimetry, 110, 601-610.

Málek, J. (1989). A computer program for kinetic analysis of non-isothermal thermoanalytical data, Thermochimica Acta, 138, 337-346. 
Málek, J., Criado, J.M., Šesták, J., Militký, J. (1989). The boundary conditions for kinetic models, Thermochimica Acta, 153, 429-432.

Málek, J. (1989). The glass transition and crystallization of germanium-sulphur glasses, Journal of Non-Crystalline Solids, 107, 323-327.

Málek, J. (1992). The kinetic analysis of non-isothermal data, Thermochimica Acta, 200, 257-269.

Martin, G., Mirodatos, C., Praliaud, H. (1981). Chemistry of silica-supported catalysts: preparation, activation and reduction, Applied Catalysis, 1, 367-382.

Matsumura, Y., Tanaka, K., Tode, N., Yazawa, T., Haruta, M. (2000). Catalytic methanol decomposition to carbon monoxide and hydrogen over nickel supported on silica, Journal of Molecular Catalysis A: Chemical, 152, 157-165.

Misono, M. (2013). Studies in Surface Science and Catalysis. Heterogeneous Catalysis of Mixed Oxides - Perovskite and Heteropoly Catalysts. Misono, M. (Ed.), Vol. 176, Elsevier, Amsterdam, The Netherlands, pp. 1-181.

Moulder, J.F., Stickle, W.F., Sobol, P.E., Bomben, K.D. (1978). Handbook of X-ray Photoelectron Spectroscopy, Chastain, J. (Ed.), Perkin-Elmer Corp., MN, USA, pp. 7595.

Munteanu, G., Ilieva, L., Nedyalkova, R., Andreeva, D. (2004). Influence of gold on the reduction behavior of $\mathrm{Au}-\mathrm{V}_{2} \mathrm{O}_{5} / \mathrm{CeO}_{2}$ catalytic systems: TPR and kinetic parameters, Applied Catalysis A: General, 227, 31-40.

Munteanu, G., Segal, E. (2010). Sestak-Berggren function in temperature-programmed reduction, Journal of Thermal Analysis and Calorimetry, 101, 89-95. 
Nakagawa, Y., Nakazawa, H., Watanabe, H., Tomishige, K. (2012). Total hydrogenation of furfural over a silica-supported nickel catalyst prepared by the reduction of a nickel nitrate precursor, ChemCatChem - Catalysis, 4, 1791-1797.

Nele, M., Vidal, A., Bhering, D.L., Pinto, J.C., Salim, V.M.M. (1999). Preparation of high loading silica-supported nickel catalyst: simulataneous analysis of the precipitation and aging steps, Applied Catalysis A: General, 178, 177-189.

Robertson, S.D., McNicol, B.D., De Baas, J.H., Kloet, S.C., Jenkins, J.W. (1975).

Determination of reducibility and identification of alloying in copper-nickel-on-silica catalysts by temperature-programmed reduction, Journal of Catalysis, 37, 424-431. Rooksby, H.P. (1943). Structure of NiO, Nature (London), 152, 304-305.

Scott, D.M., Lau, S.S., Pfeffer, R.L., Lux, R.A., Mikkelson, J., Wieluński, L., Nicolet, M.-A. (1983). The effects of interfacial $\mathrm{SiO}_{2}$ on $\mathrm{Pd}_{2} \mathrm{Si}$ formation, Thin Solid Films, 104, 227-233.

Senum, G.I., Yang, R.T. (1979). Rational approximation of the integral of the Arrhenius function, Journal of Thermal Analysis and Calorimetry, 11, 445-447.

Stanković, M., Gabrovska, M., Krstić, J., Tzvetkov, P., Shopska, M., Tsacheva, T., Banković, P., Edreva-Kardjieva, R., Jovanović, D. (2009). Effect of silver modification on structure and catalytic performance of Ni-Mg/diatomite catalysts for edible oil hydrogenation, Journal of Molecular Catalysis A: Chemical, 297, 54-62.

Stevenson, S.A., Dumesic, J.A., Baker, R.T.K., Ruckenstein, E. (1989). Metal-Support Interactions in Catalysis, Sintering, and Redispersion, Van Nostrand, New York, pp. 5964. 
Szekely, J., Lin, C.I., Sohn, H.Y. (1973). A structural model for gas-solid reactions with a moving boundary- $\mathrm{V}$ an experimental study of the reduction of porous nickel-oxide pellets with hydrogen, Chemical Engineering Science, 28, 1975-1989.

Szekely, J., Evans, J.W. (1971). Studies in gas-solid reactions: Part I. A structural model for the reaction of porous oxides with a reducing gas, Metallurgical and Materials Transactions B, 2, 1691-1698.

Šesták, J., Berggren, G. (1971). Study of the kinetics of the mechanism of solid-state reactions at increasing temperatures, Thermochimica Acta, 3, 1-12.

Šesták, J., Šatava, V., Wendlandt, W.W. (1973). The study of heterogeneous processes by thermal analysis, Thermochimica Acta, 7, 333-336.

Thomas, J.M., Thomas, W.J. (1997). Principles and Practice of Heterogeneous Catalysis, WHC Verlag GmbH, Weinheim, pp. 32-43.

Tien, R.H., Turkdogan, E.T. (1972). Gaseous reduction of iron oxides: Part IV. Mathematical analysis of partial internal reduction - diffusion control, Metallurgical and Materials Transactions B, 3, 2039-2048.

Ueckert, T., Lamber, R., Jaeger, N.I., Schubert, U. (1997). Strong metal support interactions in a $\mathrm{Ni} / \mathrm{SiO}_{2}$ catalyst prepared via sol-gel synthesis, Applied Catalysis A: General, 155, 75-85.

Vlaev, L., Georgieva, V., Genieva, S. (2007). Products and kinetics of non-isothermal decomposition of vanadium (IV) oxide compounds, Journal of Thermal Analysis and Calorimetry, 88, 805-812.

Vyazovkin, S., Wight, C.A. (1997). Kinetics In Solids, Annual Review of Physical Chemistry, 48, 125-149. 
Vyazovkin, S. (2000). Kinetic concepts of thermally stimulated reactions in solids: A view from historical perspective, International Reviews in Physical Chemistry, 19, 45-60. Vyazovkin, S., Wight, C.A. (1999). Model-free and model-fitting approaches to kinetic analysis of isothermal and nonisothermal data, Thermochimica Acta, 340-341, 53-68. Wang, H., Jiao, X., Chen, D. (2008). Monodispersed nickel nanoparticles with tunable phase and size: Synthesis, characterization, and magnetic properties, Journal of Physical Chemistry C, 112, 18793-18797.

Weatherbee, G.D., Bartholomew, C.H. (1984). Effects of support on hydrogen adsorption/desorption kinetics of nickel, Journal of Catalysis, 87, 55-65. Yamashina, Y., Nagamatsuya, T. (1966). Hydrogen reduction of nickel oxide doped and mixed with cupric oxide, Journal of Physical Chemistry, 70, 3572-3575.

Zhou, L., Rai, A., Piekiel, N., Ma, X., Zachariah, M.R. (2008). Ion-mobility spectrometry of nickel nanoparticle oxidation kinetics: Application to energetic materials, Journal of Physical Chemistry C, 112, 16209-16218.

Zieliński, J. (1995). Reductibility of silica supported nickel oxide. Catalysis Letters, 31, 47-56. 
Table I. Expressions for $f(\alpha)$ and $g(\alpha)$ functions for some of the common mechanisms operating in the solid state reactions

\begin{tabular}{|c|c|c|c|c|}
\hline No. & Symbol & Reaction models & $f(\alpha)$ & $g(\alpha)$ \\
\hline 1 & P1 & Power law & $4 \alpha^{3 / 4}$ & $\alpha^{1 / 4}$ \\
\hline 2 & $\mathrm{P} 2$ & Power law & $3 \alpha^{2 / 3}$ & $\alpha^{1 / 3}$ \\
\hline 3 & P3 & Power law & $2 \alpha^{1 / 2}$ & $\alpha^{1 / 2}$ \\
\hline 4 & $\mathrm{P} 4$ & Power law & $2 / 3 \alpha^{-1 /}$ & $\alpha^{3 / 2}$ \\
\hline 5 & R1 & Zero-order (Polany-Winger equation) & & $\alpha$ \\
\hline 6 & R2 & $\begin{array}{l}\text { Phase-boundary controlled reaction (contracting } \\
\text { area, i.e., bidimensional shape) }\end{array}$ & $2(1-\alpha)^{1 / 2}$ & {$\left[1-(1-\alpha)^{1 / 2}\right]$} \\
\hline 7 & R3 & $\begin{array}{l}\text { Phase-boundary controlled reaction (contracting } \\
\text { volume, i.e., tridimensional shape) }\end{array}$ & $3(1-\alpha)^{2 / 3}$ & {$\left[1-(1-\alpha)^{1 / 3}\right]$} \\
\hline 8 & F1 & First-order (Mampel) & $(1-\alpha)$ & $-\ln (1-\alpha)$ \\
\hline 9 & $\mathrm{~F} 3 / 2$ & Three-halves order & $(1-\alpha)^{3 / 2}$ & $\begin{array}{l}2\left[(1-\alpha)^{-1 / 2}-\right. \\
1]\end{array}$ \\
\hline 10 & $\mathrm{~F} 2$ & Second-order & $(1-\alpha)^{2}$ & $(1-\alpha)^{-1}-1$ \\
\hline 11 & F3 & Third-order & $(1-\alpha)^{3}$ & $\begin{array}{l}(1 / 2)\left[(1-\alpha)^{-2}\right. \\
-1]\end{array}$ \\
\hline 12 & $\mathrm{~A} 3 / 2$ & Avrami-Erofe'ev $(M=1.5)$ & $\begin{array}{l}(3 / 2)(1-\alpha)[-\ln \\
(1-\alpha)]^{1 / 3}\end{array}$ & {$[-\ln (1-\alpha)]^{2 / 3}$} \\
\hline 13 & A2 & Avrami-Erofe'ev $(M=2)$ & $\begin{array}{l}2(1-\alpha)[-\ln (1- \\
\alpha)]^{1 / 2}\end{array}$ & {$[-\ln (1-\alpha)]^{1 / 2}$} \\
\hline 14 & A3 & Avrami-Erofe'ev $(M=3)$ & $3(1-\alpha)[-\ln (1-$ & {$[-\ln (1-\alpha)]^{1 / 3}$} \\
\hline
\end{tabular}




\begin{tabular}{|l|l|l|l|l|}
\hline & & & $\alpha)]^{2 / 3}$ & \\
\hline 15 & A4 & Avrami-Erofe'ev $(M=4)$ & $\begin{array}{l}4(1-\alpha)[-\ln (1- \\
\alpha)]^{3 / 4}\end{array}$ & {$[-\ln (1-\alpha)]^{1 / 4}$} \\
\hline 16 & D1 & One-dimensional diffusion & $1 / 2 \alpha$ & $\alpha^{2}$ \\
\hline 17 & D2 & Two-dimensional diffusion (bidimensional & $1 /[-\ln (1-\alpha)]$ & $(1-\alpha) \ln (1-$ \\
& & particle shape) Valensi equation & $\alpha)+\alpha$ \\
\hline 18 & D3 & Three-dimensional diffusion (tridimensional & $3(1-\alpha)^{1 / 3} / 2[(1-$ & {$\left[1-(1-\alpha)^{1 / 3}\right]^{2}$} \\
& & particle shape) Jander equation & $\left.\alpha)^{-1 / 3}-1\right]$ & \\
\hline
\end{tabular}


Table II. The characteristic temperature values for the reduction process of Ni catalyst precursors synthesized with different $\mathrm{SiO}_{2} / \mathrm{Ni}$ molar ratios

\begin{tabular}{|c|c|c|c|c|c|c|c|c|c|}
\hline \multicolumn{10}{|c|}{ olar ratios } \\
\hline \multirow{2}{*}{$\begin{array}{l}\beta \\
\left({ }^{\circ} \mathrm{Cmin}^{-}\right. \\
\left.{ }^{1}\right)\end{array}$} & \multicolumn{3}{|c|}{$\mathrm{SiO}_{2} / \mathrm{Ni}=0.20$} & \multicolumn{3}{|c|}{$\mathrm{SiO}_{2} / \mathrm{Ni}=\mathbf{0 . 8 0}$} & \multicolumn{3}{|c|}{$\mathrm{SiO}_{2} / \mathrm{Ni}=1.15$} \\
\hline & $\begin{array}{l}T_{i} \\
\left({ }^{\circ} \mathbf{C}\right)\end{array}$ & $\begin{array}{l}T_{p} \\
\left({ }^{\circ} \mathbf{C}\right)\end{array}$ & $\begin{array}{l}T_{f} \\
\left({ }^{\circ} \mathbf{C}\right)\end{array}$ & $\begin{array}{l}T_{i} \\
\left({ }^{\circ} \mathrm{C}\right)\end{array}$ & $\begin{array}{l}T_{p} \\
\left({ }^{\circ} \mathrm{C}\right)\end{array}$ & $\begin{array}{l}T_{f} \\
\left({ }^{\circ} \mathbf{C}\right)\end{array}$ & $\begin{array}{l}T_{i} \\
\left({ }^{\circ} \mathrm{C}\right)\end{array}$ & $\begin{array}{l}T_{p} \\
\left({ }^{\circ} \mathrm{C}\right)\end{array}$ & $\left({ }^{\circ} \mathrm{C}\right)$ \\
\hline 2 & 212.96 & 265.35 & 299.73 & 222.59 & 265.05 & 280.58 & 210.59 & 263.09 & 283.58 \\
\hline 5 & 227.37 & 274.45 & 306.93 & 233.85 & 274.16 & 302.76 & 222.19 & 277.25 & 296.40 \\
\hline 10 & 233.15 & 284.53 & 323.51 & 236.64 & 283.36 & 305.00 & 230.86 & 286.96 & 303.17 \\
\hline 20 & 255.27 & 304.71 & 359.04 & 255.20 & 301.68 & 330.73 & 254.66 & 303.73 & 340.53 \\
\hline
\end{tabular}


Table III. The relative mass loss of the samples with given $\mathrm{SiO}_{2} / \mathrm{Ni}$ molar ratios and calculated precursor composition according to the general formula of basic nickel carbonate/nickel hydroxide, $\mathrm{NiCO}_{3} \cdot X \mathrm{Ni}(\mathrm{OH})_{2} \cdot Y \mathrm{H}_{2} \mathrm{O}$

\begin{tabular}{|l|l|l|l|}
\hline $\begin{array}{l}\text { Molar ratio } \\
\mathrm{SiO}_{2} / \mathrm{Ni}\end{array}$ & $\Delta \boldsymbol{m} / \boldsymbol{m}$ & $\boldsymbol{Y}$ & \\
\hline 0.20 & 0.47 & 0.47 & 2.07 \\
\hline 0.80 & 0.32 & 0.85 & 2.76 \\
\hline 1.15 & 0.27 & 1.26 & 3.20 \\
\hline
\end{tabular}


Table IV. Values of the compensation effect parameters at the four different heating rates $\left(\beta=2,5,10\right.$ and $\left.20^{\circ} \mathrm{C} \mathrm{min}^{-1}\right)$ for the reduction process of Ni catalyst precursors synthesized with different $\mathrm{SiO}_{2} / \mathrm{Ni}$ molar ratios

\begin{tabular}{|c|c|c|c|c|}
\hline \multicolumn{5}{|c|}{$\mathrm{SiO}_{2} / \mathrm{Ni}=0.20$} \\
\hline $\begin{array}{l}\beta\left({ }^{\circ} \mathrm{Cmin}^{-}\right. \\
\left.{ }^{1}\right)\end{array}$ & $\alpha^{*}\left(\min ^{-1}\right)$ & $\beta^{* \prime}\left(\right.$ molkJ $\left.^{-1}\right)$ & $\begin{array}{l}T_{\text {iso }} \\
\left({ }^{\circ} \mathrm{C}\right)\end{array}$ & $R^{2 \mathrm{a}}$ \\
\hline 2 & $\begin{array}{l}-3.37033 \pm \\
0.43847\end{array}$ & $\begin{array}{l}0.22497 \pm \\
0.00202\end{array}$ & 261.48 & 0.99855 \\
\hline 5 & $\begin{array}{l}-2.35593 \pm \\
0.43999\end{array}$ & $\begin{array}{l}0.22131 \pm \\
0.00181\end{array}$ & 270.33 & 0.99880 \\
\hline 10 & $\begin{array}{l}-1.91092 \pm \\
0.43905\end{array}$ & $\begin{array}{l}0.21785 \pm \\
0.00217\end{array}$ & & 0.99822 \\
\hline 20 & $\begin{array}{l}-1.30348 \pm \\
0.43885\end{array}$ & $\begin{array}{l}0.20992 \pm \\
0.00213\end{array}$ & 299.82 & 0.99816 \\
\hline \multicolumn{5}{|c|}{$\mathrm{SiO}_{2} / \mathrm{Ni}=\mathbf{0 . 8 0}$} \\
\hline $\begin{array}{l}\beta\left({ }^{\circ} \mathrm{Cmin}^{-}\right. \\
\left.{ }^{1}\right)\end{array}$ & $\alpha^{*}\left(\min ^{-1}\right)$ & $\beta^{*}\left(\right.$ molkJ $\left.^{-1}\right)$ & $\begin{array}{l}\mathrm{T}_{\text {iso }} \\
\left({ }^{\circ} \mathrm{C}\right)\end{array}$ & $R^{2 \mathrm{a}}$ \\
\hline 2 & $\begin{array}{l}-2.99214 \pm \\
0.44236\end{array}$ & $\begin{array}{l}0.22549 \pm \\
0.00148\end{array}$ & 260.25 & 0.99922 \\
\hline 5 & $\begin{array}{l}-2.37681 \pm \\
0.43765\end{array}$ & $\begin{array}{l}0.22209 \pm \\
0.00182\end{array}$ & 268.42 & 0.99880 \\
\hline 10 & $\begin{array}{l}-1.51616 \pm \\
0.44081\end{array}$ & $\begin{array}{l}0.21815 \pm \\
0.00164\end{array}$ & 278.20 & 0.99898 \\
\hline
\end{tabular}




\begin{tabular}{|c|c|c|c|c|}
\hline 20 & $\begin{array}{l}-1.07704 \pm \\
0.44079\end{array}$ & $\begin{array}{l}0.21097 \pm \\
0.00174\end{array}$ & 296.96 & 0.99878 \\
\hline \multicolumn{5}{|c|}{$\mathrm{SiO}_{2} / \mathrm{Ni}=1.15$} \\
\hline $\begin{array}{l}\beta\left({ }^{\circ} \mathrm{Cmin}^{-}\right. \\
\left.{ }^{1}\right)\end{array}$ & $\alpha^{*}\left(\min ^{-1}\right)$ & $\beta^{*}\left(\right.$ molkJ $\left.J^{-1}\right)$ & $\begin{array}{l}T_{\text {iso }} \\
\left({ }^{0} \mathrm{C}\right)\end{array}$ & $R^{2 \mathrm{a}}$ \\
\hline 2 & $\begin{array}{l}-3.21309 \pm \\
0.43985\end{array}$ & $\begin{array}{l}0.22645 \pm \\
0.00190\end{array}$ & 258.00 & 0.99874 \\
\hline 5 & $\begin{array}{l}-2.30575 \pm \\
0.44276\end{array}$ & $\begin{array}{l}0.22114 \pm \\
0.00175\end{array}$ & 270.75 & 0.99887 \\
\hline 10 & $\begin{array}{l}-1.80859 \pm \\
0.43798\end{array}$ & $\begin{array}{l}0.21828 \pm \\
0.00209\end{array}$ & 277.87 & 0.99836 \\
\hline 20 & $\begin{array}{l}-1.22053 \pm \\
0.44014\end{array}$ & $\begin{array}{l}0.21026 \pm \\
0.00201\end{array}$ & 298.89 & 0.99837 \\
\hline
\end{tabular}

${ }^{\mathrm{a}} R^{2}-$ Adj. R-Square; 
Table $\mathrm{V}$. The invariant kinetic parameters $\left(E_{a, i s o}, A_{i s o}\right)$ values evaluated from the supercorellation relation (Eq. (5)) for the reduction process of Ni catalyst precursors synthesized with different $\mathrm{SiO}_{2} / \mathrm{Ni}$ molar ratios

\begin{tabular}{|c|c|c|}
\hline \multicolumn{3}{|c|}{$\mathrm{SiO}_{2} / \mathrm{Ni}=0.20$} \\
\hline $\ln A_{\text {iso }}$ & $\begin{array}{l}A_{\text {iso }}\left(\mathrm{min}^{-}\right. \\
\left.\mathrm{1}^{-}\right)\end{array}$ & $\begin{array}{l}E_{a, i s o} \\
\left(\mathrm{kJmol}^{-1}\right)\end{array}$ \\
\hline 25.81 & $\begin{array}{l}1.62 \times \\
10^{11}\end{array}$ & $128.3 \pm 1.5$ \\
\hline \multicolumn{3}{|c|}{$\mathrm{SiO}_{2} / \mathrm{Ni}=0.80$} \\
\hline $\ln A_{\text {iso }}$ & $\begin{array}{l}A_{\text {iso }}\left(\mathrm{min}^{-}\right. \\
\left.\mathrm{1}^{-}\right)\end{array}$ & $\begin{array}{l}E_{a, i s o} \\
\left(\mathrm{kJmol}^{-1}\right)\end{array}$ \\
\hline 26.98 & $\begin{array}{l}5.21 \times \\
10^{11}\end{array}$ & $132.2 \pm 1.7$ \\
\hline \multicolumn{3}{|c|}{$\mathrm{SiO}_{2} / \mathrm{Ni}=1.15$} \\
\hline $\ln A_{\text {iso }}$ & $\begin{array}{l}A_{\text {iso }}\left(\min ^{-}\right. \\
\text {1) }^{-}\end{array}$ & $\begin{array}{l}E_{a, i s o} \\
\left(\mathrm{kJmol}^{-1}\right)\end{array}$ \\
\hline 24.45 & $4.15 \times$ & $121.4 \pm 2.0$ \\
\hline
\end{tabular}


Table VI. Values of $\alpha_{m}, \alpha_{p}^{\infty}$ and $\alpha_{p}$ estimated for the reduction process of Ni catalyst precursors, synthesized with different $\mathrm{SiO}_{2} / \mathrm{Ni}$ molar ratios under hydrogen atmosphere at the different heating rates

\begin{tabular}{|c|c|c|c|c|c|c|c|c|c|}
\hline \multirow{2}{*}{$\begin{array}{l}B \\
\left({ }^{\circ} \mathrm{Cmin}^{-}\right. \\
\left.{ }^{1}\right)\end{array}$} & \multicolumn{3}{|c|}{$\mathrm{SiO}_{2} / \mathrm{Ni}=\mathbf{0 . 2 0}$} & \multicolumn{3}{|c|}{$\mathrm{SiO}_{2} / \mathrm{Ni}=\mathbf{0 . 8 0}$} & \multicolumn{3}{|c|}{$\mathrm{SiO}_{2} / \mathrm{Ni}=1.15$} \\
\hline & $\boldsymbol{\alpha}_{m}$ & $\boldsymbol{\alpha}_{p}^{\infty}$ & $\boldsymbol{\alpha}_{p}$ & $\boldsymbol{\alpha}_{m}$ & $\boldsymbol{\alpha}_{p}^{\infty}$ & $\boldsymbol{\alpha}_{p}$ & $\boldsymbol{\alpha}_{m}$ & $\boldsymbol{\alpha}_{p}^{\infty}$ & $\alpha_{p}$ \\
\hline 2 & 0.254 & $\begin{array}{l}0.52 \\
6\end{array}$ & $\begin{array}{l}0.47 \\
7\end{array}$ & $\begin{array}{l}0.32 \\
7\end{array}$ & $\begin{array}{l}0.56 \\
7\end{array}$ & $\begin{array}{l}0.56 \\
7\end{array}$ & $\begin{array}{l}0.28 \\
3\end{array}$ & $\begin{array}{l}0.58 \\
5\end{array}$ & $\begin{array}{c}0.54 \\
5\end{array}$ \\
\hline 5 & 0.301 & $\begin{array}{l}0.49 \\
9\end{array}$ & $\begin{array}{l}0.49 \\
9\end{array}$ & $\begin{array}{l}0.27 \\
0\end{array}$ & $\begin{array}{l}0.54 \\
1\end{array}$ & $\begin{array}{l}0.54 \\
1\end{array}$ & 0.31 & $\begin{array}{l}0.58 \\
0\end{array}$ & $\begin{array}{l}0.58 \\
0\end{array}$ \\
\hline 10 & 0.250 & $\begin{array}{l}0.54 \\
8\end{array}$ & $\begin{array}{l}0.50 \\
2\end{array}$ & $\begin{array}{l}0.30 \\
7\end{array}$ & 0.56 & 0.56 & $\begin{array}{l}0.25 \\
2\end{array}$ & $\begin{array}{l}0.64 \\
8\end{array}$ & $\begin{array}{l}0.61 \\
3\end{array}$ \\
\hline 20 & 0.241 & $\begin{array}{l}0.51 \\
6\end{array}$ & $\begin{array}{l}0.47 \\
4\end{array}$ & 0.28 & $\begin{array}{l}0.53 \\
7\end{array}$ & $\begin{array}{l}0.49 \\
3\end{array}$ & $\begin{array}{l}0.27 \\
0\end{array}$ & $\begin{array}{l}0.53 \\
0\end{array}$ & $\begin{array}{l}0.48 \\
3\end{array}$ \\
\hline
\end{tabular}


Table VII. The kinetic exponents $(m, n)$ and reaction orders $(m+n)$ of the conversion function $f(\alpha)=\alpha^{m}(1-\alpha)^{n}$ (Eq. (14)) as well as the values of $\ln A$ and $A$, resulting from Eq. (16), for the reduction process of $\mathrm{Ni}$ catalyst precursors, synthesized with different $\mathrm{SiO}_{2} / \mathrm{Ni}$ molar ratios under hydrogen atmosphere, at the heating rates of $\beta=2,5,10$ and $20{ }^{\circ} \mathrm{C} \min ^{-1}$

\begin{tabular}{|c|c|c|c|c|c|c|}
\hline \multicolumn{7}{|c|}{$\mathrm{SiO}_{2} / \mathrm{Ni}=0.20$} \\
\hline $\begin{array}{l}\beta\left({ }^{\circ} \mathrm{Cmin}^{-}\right. \\
\left.{ }^{1}\right)\end{array}$ & $m$ & $n$ & $\begin{array}{l}m+ \\
n\end{array}$ & $\ln A$ & $A\left(\min ^{-1}\right)$ & $R^{2 \mathrm{a}}$ \\
\hline 2 & 0.48 & $\begin{array}{l}1.40 \pm \\
0.01\end{array}$ & 1.88 & 28.48 & $\begin{array}{l}2.34 \times \\
10^{12}\end{array}$ & 0.99978 \\
\hline 5 & 0.59 & $\begin{array}{l}1.38 \pm \\
0.01\end{array}$ & 1.97 & 29.09 & $\begin{array}{l}4.30 x \\
10^{12}\end{array}$ & 0.99897 \\
\hline 10 & 0.46 & $\begin{array}{l}1.39 \pm \\
0.01\end{array}$ & 1.85 & 28.97 & $\begin{array}{l}3.81 \times \\
10^{12}\end{array}$ & 0.99963 \\
\hline 20 & 0.48 & $\begin{array}{l}1.50 \pm \\
0.01\end{array}$ & 1.98 & 28.62 & $\begin{array}{l}2.69 \times \\
10^{12}\end{array}$ & 0.99977 \\
\hline Average & 0.50 & $\begin{array}{l}1.42 \pm \\
0.01\end{array}$ & 1.92 & 28.79 & $\begin{array}{l}3.19 \times \\
10^{12}\end{array}$ & - \\
\hline \multicolumn{7}{|c|}{$\mathrm{SiO}_{2} / \mathrm{Ni}=0.80$} \\
\hline $\begin{array}{l}\beta\left({ }^{\circ} \mathrm{Cmin}^{-}\right. \\
\left.{ }^{1}\right)\end{array}$ & $m$ & $n$ & $\begin{array}{l}m+ \\
n\end{array}$ & $\ln A$ & $A\left(\min ^{-1}\right)$ & $R^{2 \mathrm{a}}$ \\
\hline 2 & 0.48 & $\begin{array}{l}0.98 \pm \\
0.01\end{array}$ & 1.46 & 29.79 & $\begin{array}{l}8.66 \times \\
10^{12}\end{array}$ & 0.99770 \\
\hline
\end{tabular}




\begin{tabular}{|c|c|c|c|c|c|c|}
\hline 5 & 0.45 & $\begin{array}{l}1.21 \pm \\
0.01\end{array}$ & 1.66 & 30.07 & $\begin{array}{l}1.15 \times \\
10^{13}\end{array}$ & 0.99901 \\
\hline 10 & 0.48 & $\begin{array}{l}1.08 \pm \\
0.01\end{array}$ & 1.56 & 30.28 & $\begin{array}{l}1.41 \times \\
10^{13}\end{array}$ & 0.99674 \\
\hline 20 & 0.51 & $\begin{array}{l}1.27 \pm \\
0.01\end{array}$ & 1.78 & 29.94 & $\begin{array}{l}1.01 \times \\
10^{13}\end{array}$ & 0.99953 \\
\hline Average & 0.48 & $\begin{array}{l}1.14 \pm \\
0.01\end{array}$ & 1.61 & 30.02 & $\begin{array}{l}1.09 \times \\
10^{13}\end{array}$ & \\
\hline \multicolumn{7}{|c|}{$\mathrm{SiO}_{2} / \mathrm{Ni}=1.15$} \\
\hline $\begin{array}{l}\beta\left({ }^{\circ} \mathrm{Cmin}^{-}\right. \\
\left.{ }^{-}\right)\end{array}$ & $m$ & $n$ & $\begin{array}{l}m+ \\
n\end{array}$ & $\ln A$ & $A\left(\min ^{-1}\right)$ & $R^{2 \mathrm{a}}$ \\
\hline 2 & 0.42 & $\begin{array}{l}1.06 \pm \\
0.01\end{array}$ & 1.48 & 27.12 & $\begin{array}{l}6.00 \times \\
10^{11}\end{array}$ & 0.99753 \\
\hline 5 & 0.46 & $\begin{array}{l}0.99 \pm \\
0.02\end{array}$ & 1.45 & 27.37 & $\begin{array}{l}7.70 \times \\
10^{11}\end{array}$ & 0.99572 \\
\hline 10 & 0.29 & $\begin{array}{l}0.85 \pm \\
0.01\end{array}$ & 1.14 & 27.23 & $\begin{array}{l}6.70 \times \\
10^{11}\end{array}$ & 0.99475 \\
\hline 20 & 0.50 & $\begin{array}{l}1.34 \pm \\
0.01\end{array}$ & 1.84 & 27.36 & $\begin{array}{l}7.63 \times \\
10^{11}\end{array}$ & 0.99956 \\
\hline Average & 0.42 & $\begin{array}{l}1.06 \pm \\
0.01\end{array}$ & 1.48 & 27.27 & $\begin{array}{l}6.97 \times \\
10^{11}\end{array}$ & - \\
\hline
\end{tabular}

${ }^{a} R^{2}-$ Adj. R-Square; 
Table VIII. Results of chemisorption analysis for Ni/D catalyst precursors ( $D$ represents the diatomite as a source of $\mathrm{SiO}_{2}$ ); The estimates of crystallite size from hydrogen chemisorption are also compared in the same table, with the values determined from the X-ray diffraction method line broadening (XRDLB)

\begin{tabular}{|c|c|c|c|c|}
\hline Sample & $\begin{array}{l}\mathbf{H}_{2} \text { uptake } \\
\left(\mu \mathrm{mol} \mathrm{g}_{\mathrm{Ni}}{ }^{-}\right. \\
\left.{ }_{1}\right)\end{array}$ & $\begin{array}{l}S_{\mathrm{Ni}}^{\mathrm{a}}\left(\mathbf{m}_{\mathrm{Ni}}^{2}\right. \\
\left.\mathrm{g}_{\mathrm{Ni}}^{-1}\right)\end{array}$ & $\begin{array}{l}\mathrm{H}_{2} \text { chem } \\
d_{s \mathrm{Ni}}{ }^{\mathrm{b}}(\mathrm{nm})\end{array}$ & $\begin{array}{l}\text { XRDLB } \\
d_{v N \mathrm{i}}^{\mathrm{c}}(\mathrm{nm})\end{array}$ \\
\hline $\mathrm{Ni} / D$ & 744.00 & 58.20 & 7.40 & 7.10 \\
\hline
\end{tabular}

${ }^{\mathrm{a}}$ Nickel surface area;

b The average size of Ni crystallites - surface-averaged values;

${ }^{\mathbf{c}}$ The average size of Ni crystallites - volume-averaged values; 
Table IX. The XPS data of the un-reduced and reduced-passivated precursors; BE binding energy in $\mathrm{eV}$ (electron-volts)

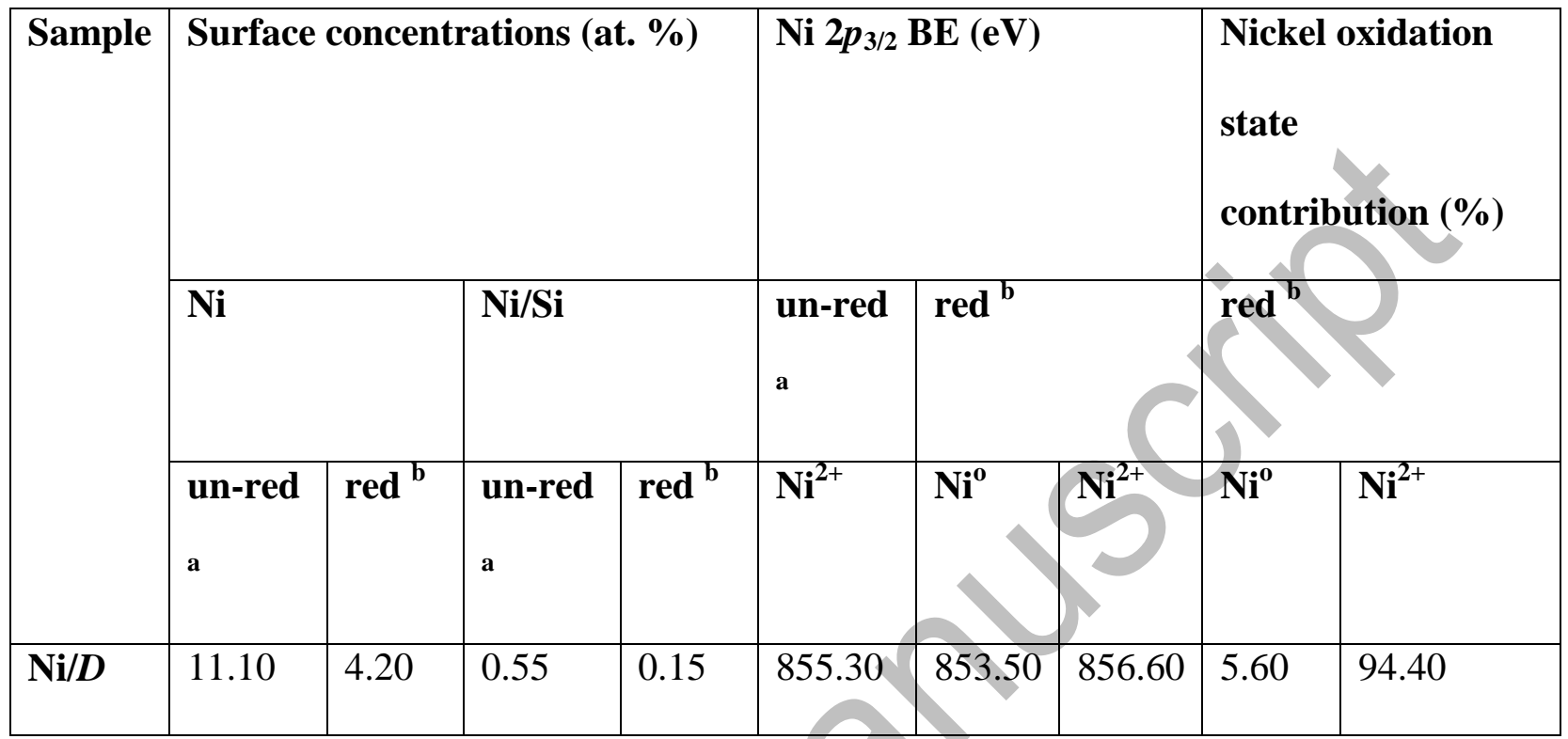

an-red: un-reduced sample;

b red: reduced sample; 
Figure 1. The non-isothermal conversion curves $(\alpha=\alpha(T))$ for the reduction process of $\mathrm{Ni}$ catalyst precursors synthesized with different $\mathrm{SiO}_{2} / \mathrm{Ni}$ molar ratios $(0.20,0.80$ and 1.15), recorded at different heating rates $\left(\beta=2,5,10\right.$ and $20{ }^{\circ} \mathrm{Cmin}^{-1}$ (from left to right)).
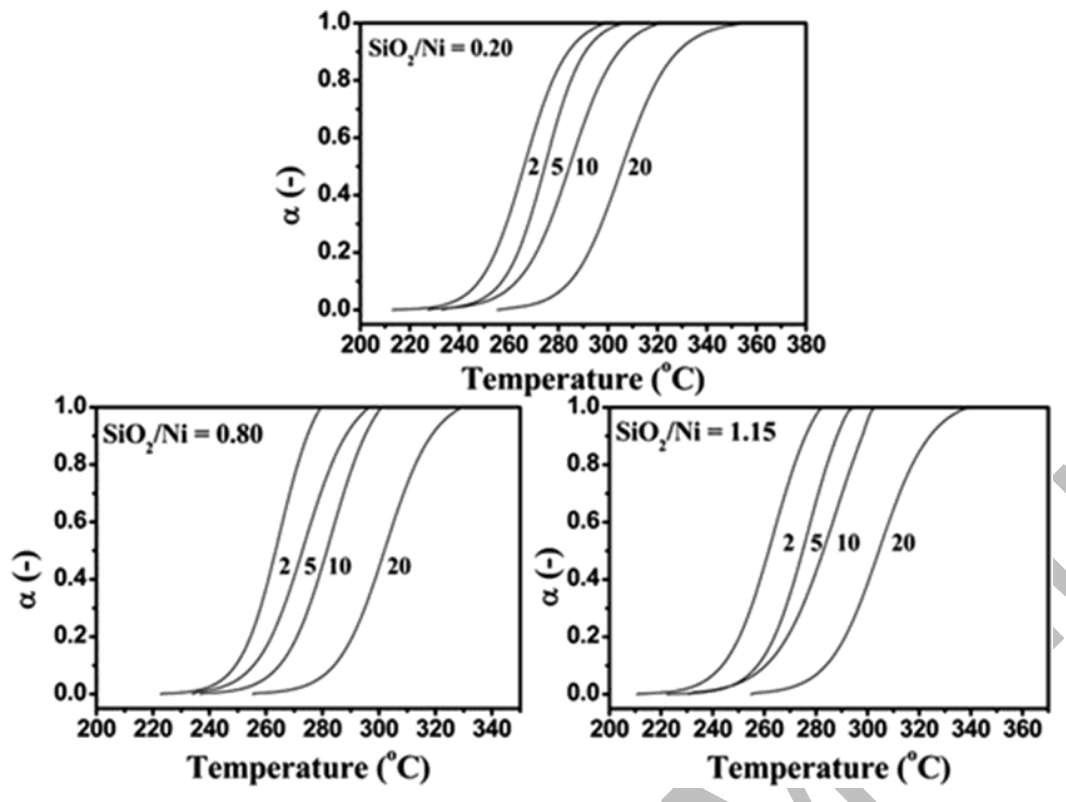
Figure 2. The dependence of the apparent activation energy $\left(E_{a}\right)$ on the degree of conversion ( $\alpha$ ), determined by the Kissinger-Akahira-Sunose (KAS) method, for different $\mathrm{SiO}_{2} / \mathrm{Ni}$ molar ratios $(0.20,0.80$ and 1.15$)$.

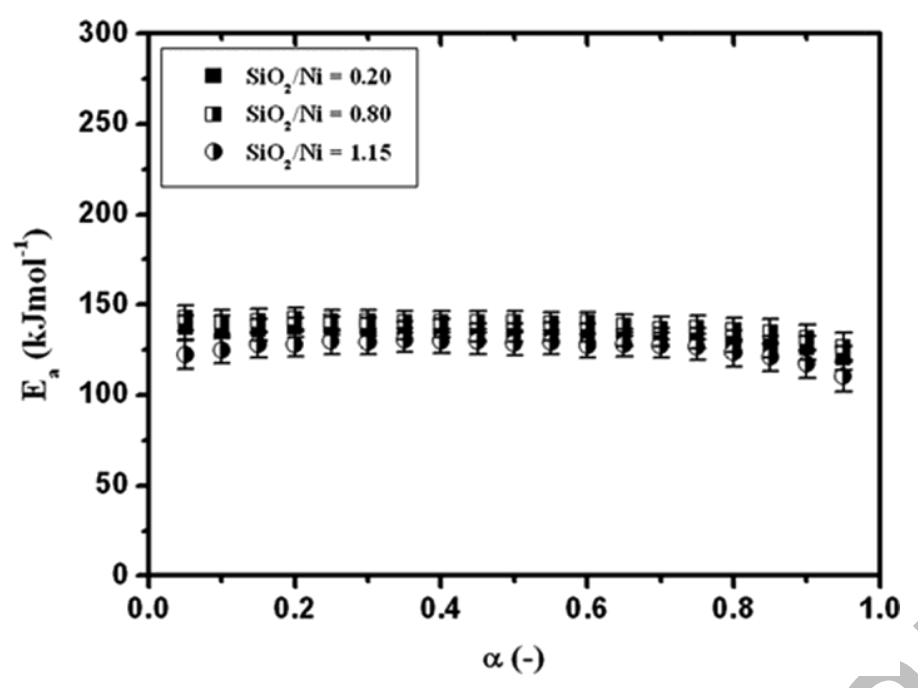


Figure 3. Dependence of $f_{\text {inv }}(\alpha)$ versus $\alpha$ for the reduction process of Ni catalyst precursors synthesized with different $\mathrm{SiO}_{2} / \mathrm{Ni}$ molar ratios $(0.20,0.80$ and 1.15), performed at different heating rates (arrow symbol represents the position of maximum of the $f_{\text {inv }}(\alpha)$ function at the corresponding $\alpha$ value).

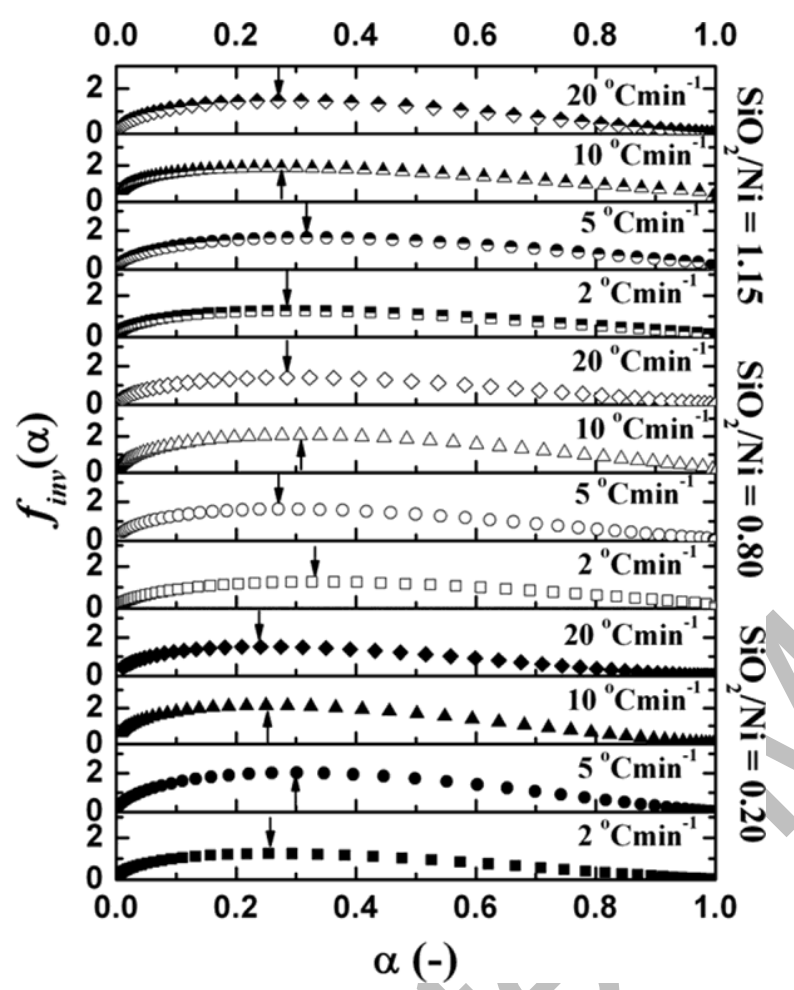


Figure 4. Normalized $y(\alpha)$ functions obtained by the transformation of the non-isothermal thermo-analytical (TA) data, for the reduction process of Ni catalyst precursor with $\mathrm{SiO}_{2} / \mathrm{Ni}=0.20$ molar ratio at different heating rates.

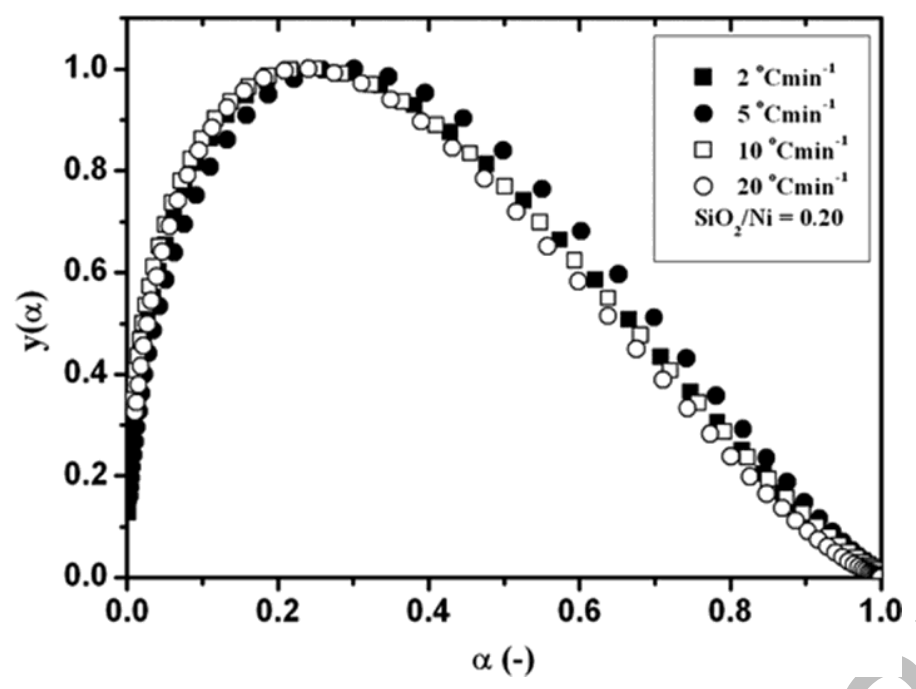


Figure 5. Normalized $y(\alpha)$ functions obtained by the transformation of the non-isothermal thermo-analytical data, for the reduction process of $\mathrm{Ni}$ catalyst precursor with $\mathrm{SiO}_{2} / \mathrm{Ni}=$ 0.80 molar ratio at different heating rates.

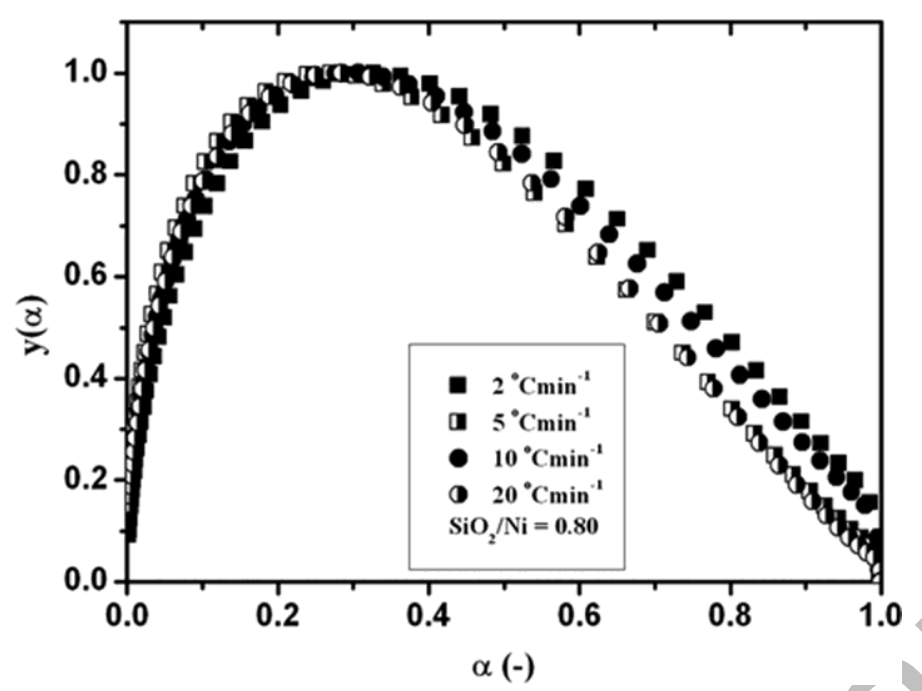


Figure 6 . Normalized $y(\alpha)$ functions obtained by the transformation of the non-isothermal thermo-analytical data, for the reduction process of $\mathrm{Ni}$ catalyst precursor with $\mathrm{SiO}_{2} / \mathrm{Ni}=$ 1.15 molar ratio at different heating rates.

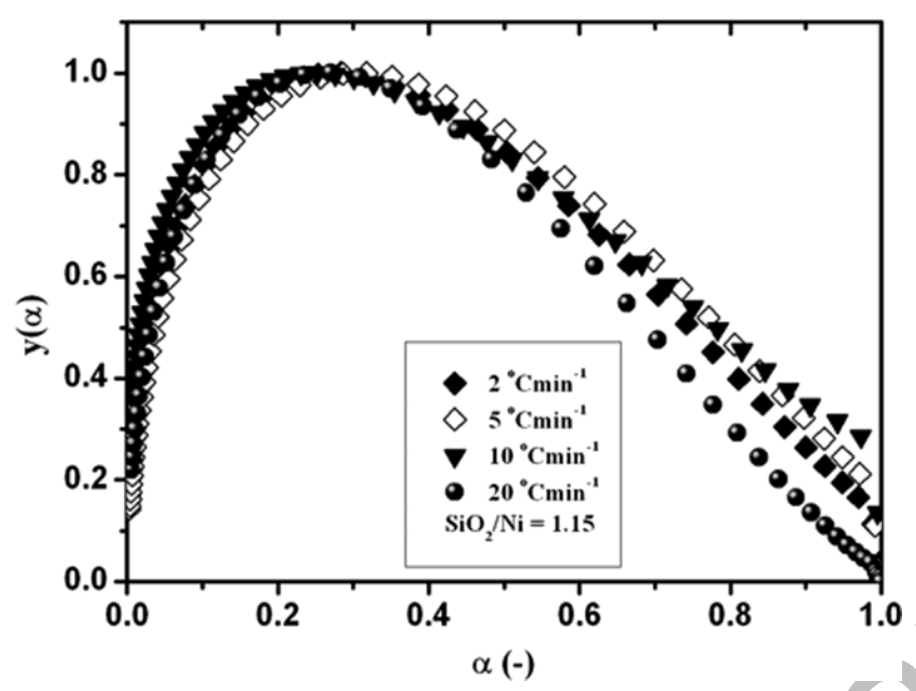


Figure 7. Normalized $z(\alpha)$ functions obtained by the transformation of the non-isothermal thermo-analytical data, for the reduction process of $\mathrm{Ni}$ catalyst precursor with $\mathrm{SiO}_{2} / \mathrm{Ni}=$ 0.20 molar ratio at different heating rates.

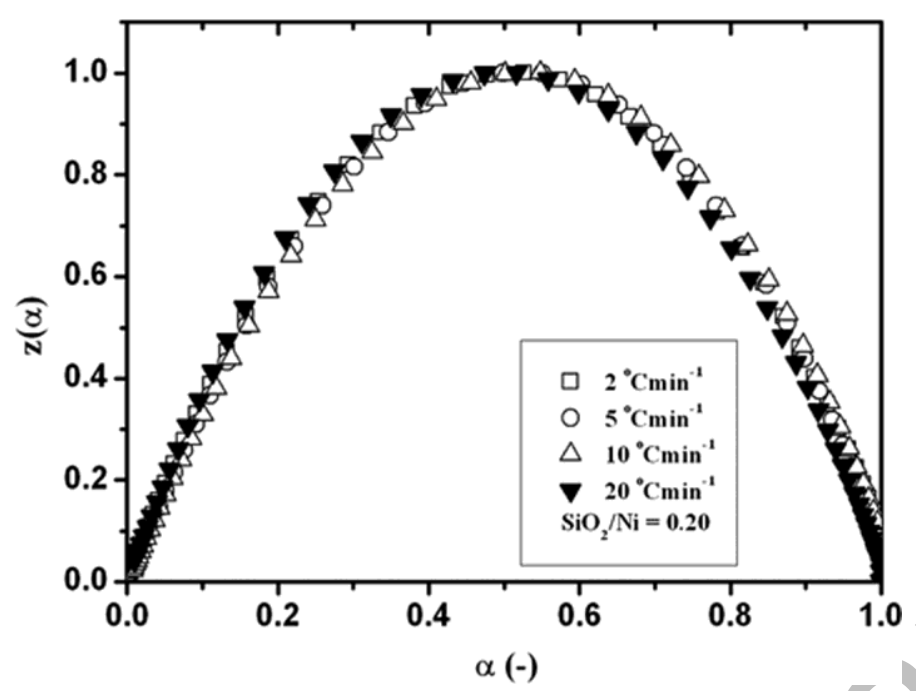


Figure 8 . Normalized $z(\alpha)$ functions obtained by the transformation of the non-isothermal thermo-analytical data, for the reduction process of $\mathrm{Ni}$ catalyst precursor with $\mathrm{SiO}_{2} / \mathrm{Ni}=$ 0.80 molar ratio at different heating rates.

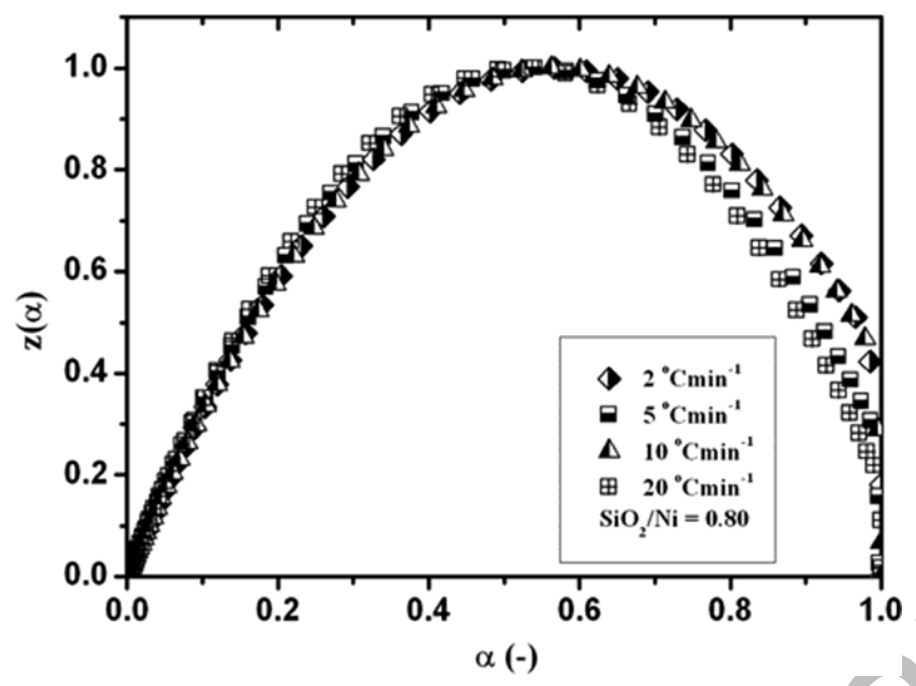


Figure 9. Normalized $z(\alpha)$ functions obtained by the transformation of the non-isothermal thermo-analytical data, for the reduction process of $\mathrm{Ni}$ catalyst precursor with $\mathrm{SiO}_{2} / \mathrm{Ni}=$ 1.15 molar ratio at different heating rates.

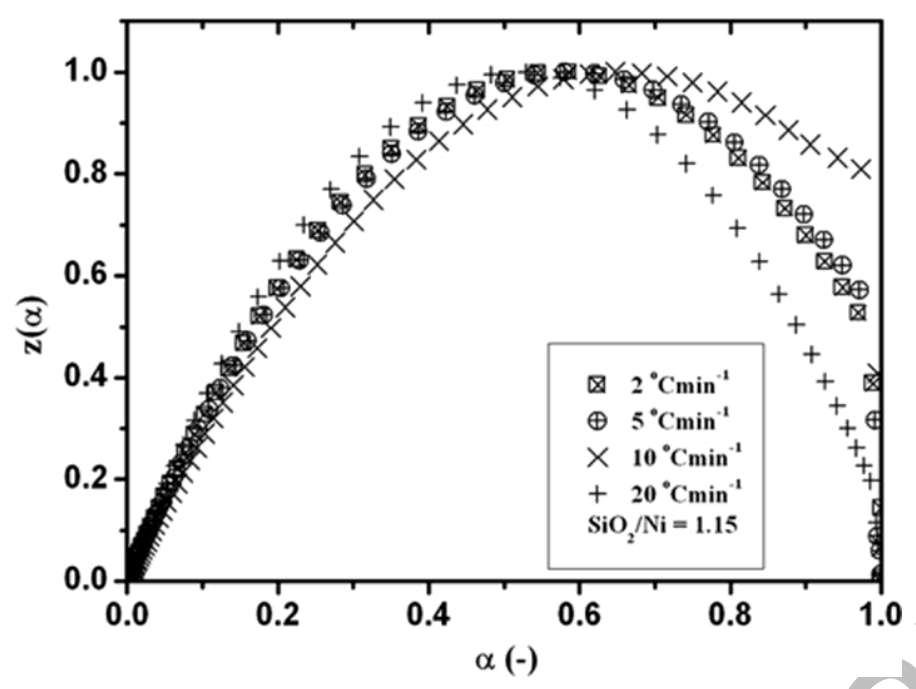


Figure 10. The SEM image with $\times 2000$ magnification and with a marker length equal to $15 \mu \mathrm{m}$, for as-synthesized $\mathrm{Ni} / D$ precursors $(D$ is the label for diatomite as a source of $\mathrm{SiO}_{2}$ ). It was taken in consideration the pattern with $\mathrm{SiO}_{2} / \mathrm{Ni}$ molar ratio equal to 1.15.

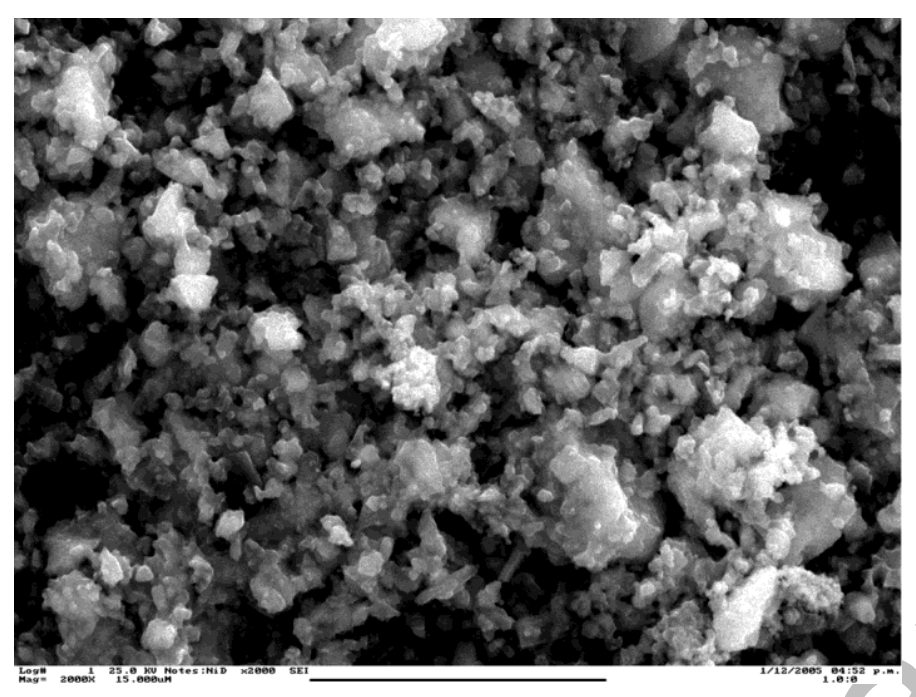


Figure 11. The SEM image with $\times 2000$ magnification and with a marker length equal to $15 \mu \mathrm{m}$, for reduced $\mathrm{Ni} / D$ precursors $\left(D\right.$ is the label for diatomite as a source of $\mathrm{SiO}_{2}$ ) annealed at $430{ }^{\circ} \mathrm{C}$. It was taken in consideration the pattern with $\mathrm{SiO}_{2} / \mathrm{Ni}$ molar ratio equal to 1.15 .

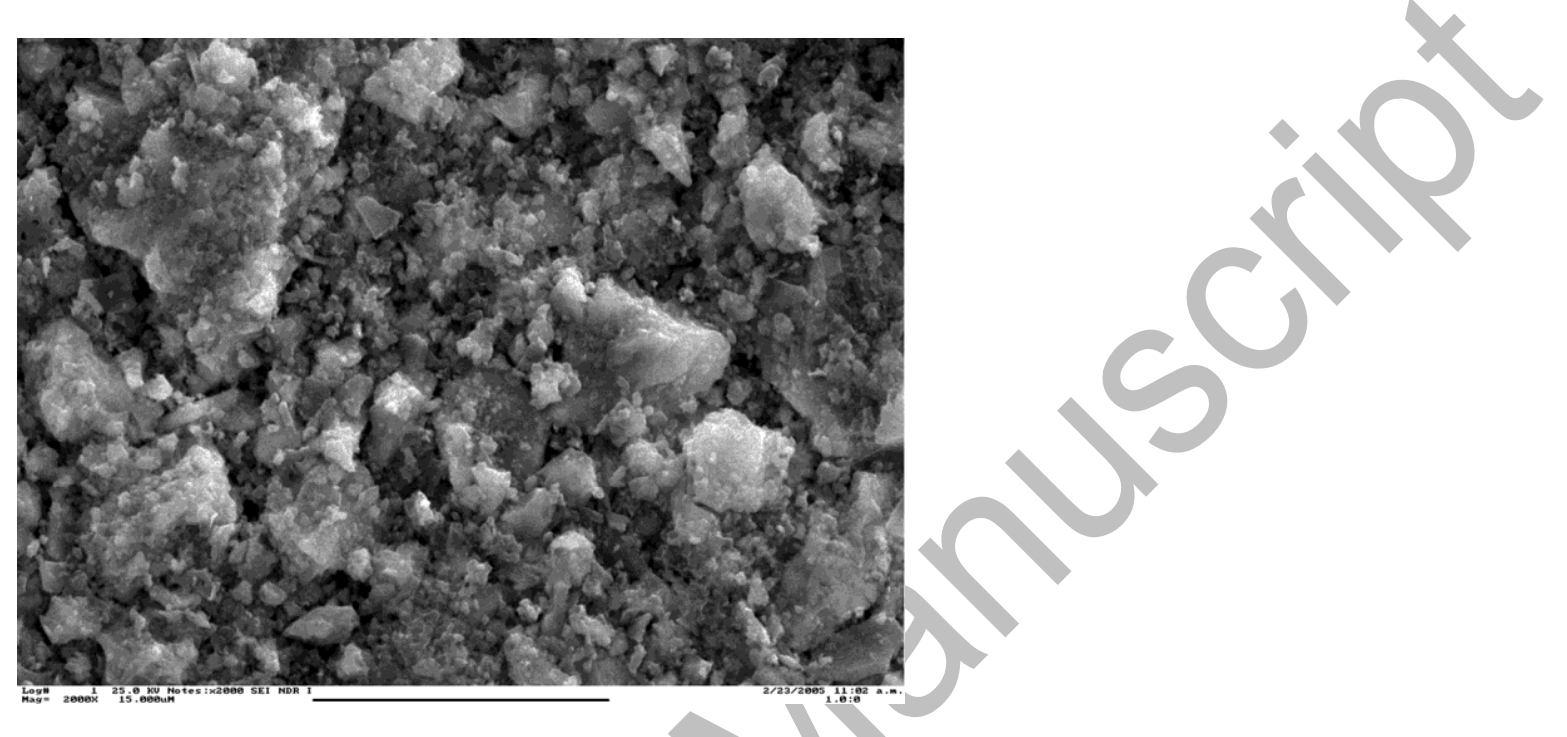


Figure 12. The XPS imaging for Ni/D catalyst precursors with data analyzed transfer (ASCII data) (square symbols (口) - DAT), the convert fitted XPS data (full black continuous line), metallic $\mathrm{Ni}$ data (symbol $-\mathrm{I}-$ ) and the oxidation state $\mathrm{Ni}^{2+}$ data (full blue continuous line). The energy scale is represented in electron-volts.

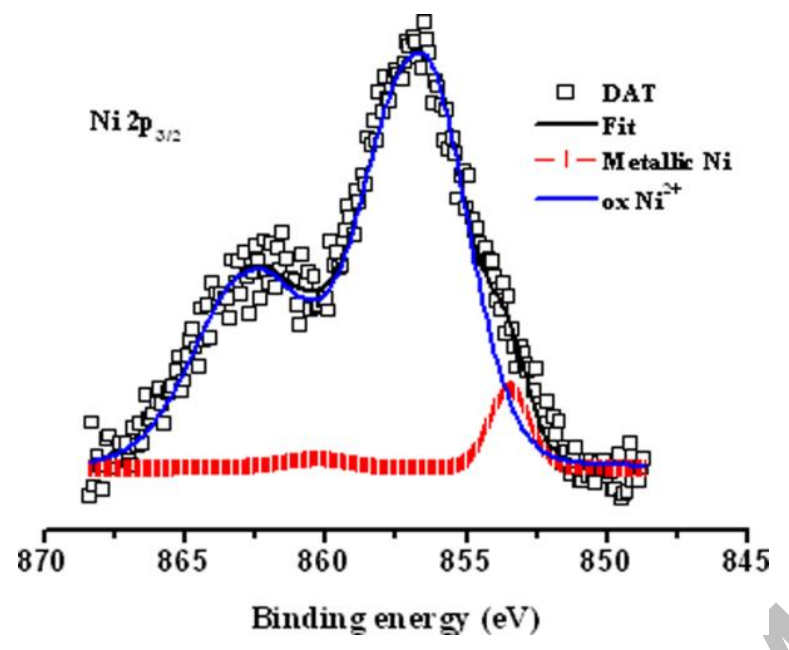

